\title{
Exploring Potential U.S. Switchgrass Production for Lignocellulosic Ethanol
}

August 2008

Prepared by

Carla A. Gunderson, Ethan B. Davis, Henriette I. Jager, Tristram O. West, Robert D. Perlack, Craig C. Brandt, Stan D. Wullschleger, Latha M.

Baskaran, Erin G. Wilkerson, and Mark E. Downing

Environmental Sciences Division

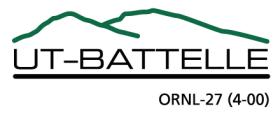




\title{
DOCUMENT AVAILABILITY
}

Reports produced after January 1, 1996, are generally available free via the U.S. Department of Energy (DOE) Information Bridge.

Web site http://www.osti.gov/bridge

Reports produced before January 1, 1996, may be purchased by members of the public from the following source.

\author{
National Technical Information Service \\ 5285 Port Royal Road \\ Springfield, VA 22161 \\ Telephone 703-605-6000 (1-800-553-6847) \\ TDD 703-487-4639 \\ Fax 703-605-6900 \\ E-mailinfo@ntis.gov \\ Web site http://www.ntis.gov/support/ordernowabout.htm
}

Reports are available to DOE employees, DOE contractors, Energy Technology Data Exchange (ETDE) representatives, and International Nuclear Information System (INIS) representatives from the following source.

Office of Scientific and Technical Information

P.O. Box 62

Oak Ridge, TN 37831

Telephone 865-576-8401

Fax 865-576-5728

E-mail reports@osti.gov

Web site http://www.osti.gov/contact.html

This report was prepared as an account of work sponsored by an agency of the United States Government. Neither the United States Government nor any agency thereof, nor any of their employees, makes any warranty, express or implied, or assumes any legal liability or responsibility for the accuracy, completeness, or usefulness of any information, apparatus, product, or process disclosed, or represents that its use would not infringe privately owned rights. Reference herein to any specific commercial product, process, or service by trade name, trademark, manufacturer, or otherwise, does not necessarily constitute or imply its endorsement, recommendation, or favoring by the United States Government or any agency thereof. The views and opinions of authors expressed herein do not necessarily state or reflect those of the United States Government or any agency thereof. 
ENVIRONMENTAL SCIENCES DIVISION

\title{
EXPLORING POTENTIAL U.S. SWITCHGRASS PRODUCTION FOR LIGNOCELLULOSIC ETHANOL
}

\author{
Carla A. Gunderson \\ Ethan B. Davis \\ Henriette I. Jager \\ Robert D. Perlack \\ Tristram O. West \\ Craig C. Brandt \\ Stan D. Wullschleger \\ Latha M. Baskaran \\ Erin G. Wilkerson \\ Mark E. Downing
}

Date Published: August 2008

\author{
Prepared by \\ OAK RIDGE NATIONAL LABORATORY \\ Oak Ridge, Tennessee 37831-6283 \\ managed by \\ UT-BATTELLE, LLC \\ for the \\ U.S. DEPARTMENT OF ENERGY \\ under contract DE-AC05-00OR22725
}




\section{CONTENTS}

Page

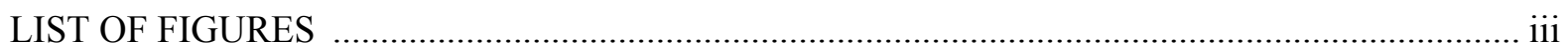

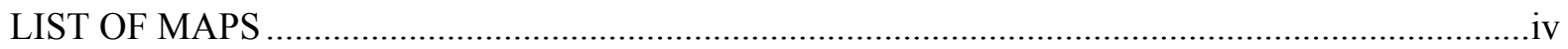

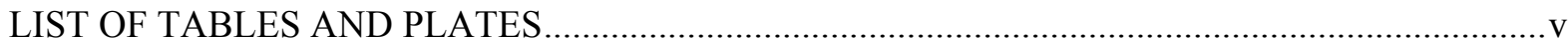

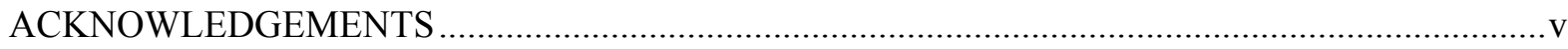

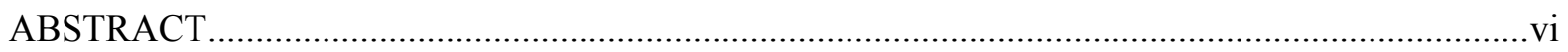

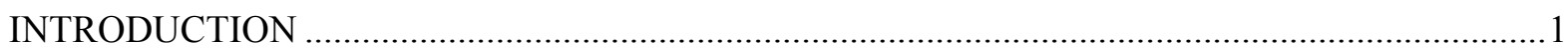

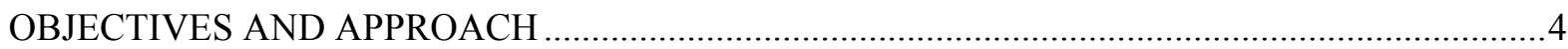

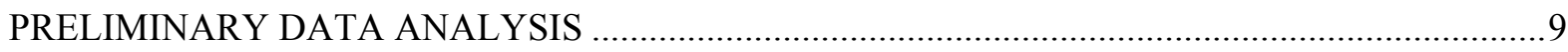

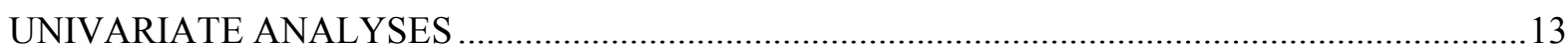

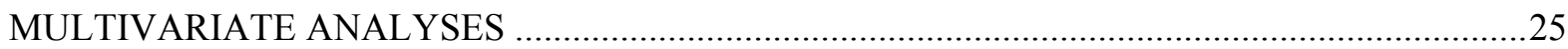

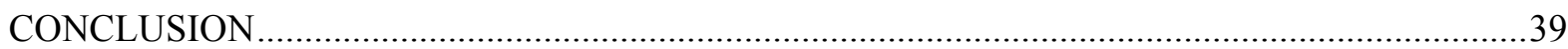

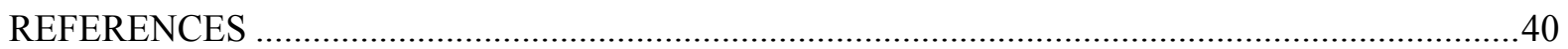




\section{LIST OF FIGURES}

Figure

Page

$1 \quad$ Frequency distribution of switchgrass dry matter yields .............................................

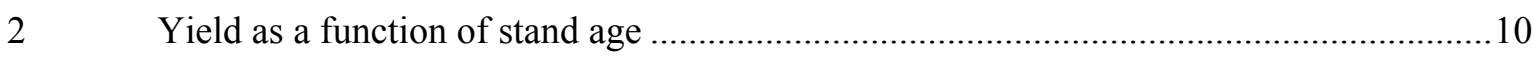

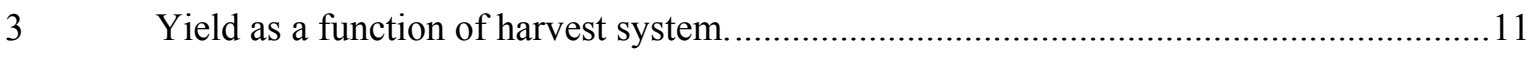

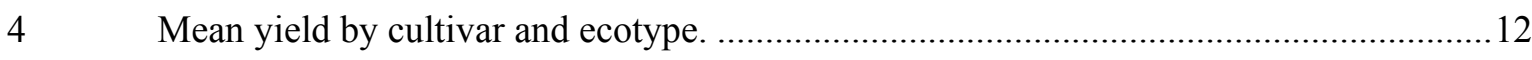

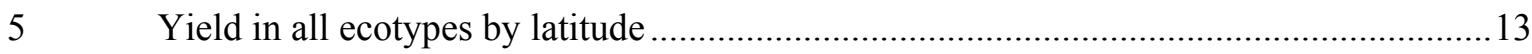

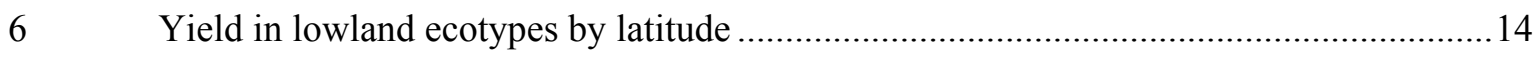

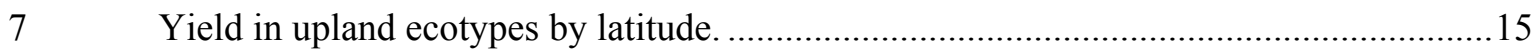

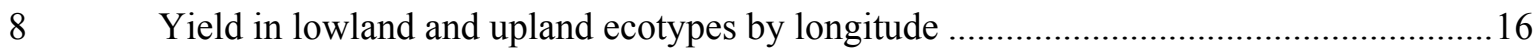

$9 \quad$ Lowland yield as a function of response to added nitrogen (and detail) .........................18

$10 \quad$ Upland yield as a function of response to added nitrogen .............................................19

11 Yield as a function of April-September total precipitation ...........................................20

12 Yield in lowland ecotype as a function of total precipitation, April- September.............21

13 Yield in upland ecotype as a function of total precipitation, April- September...............21

14 Yield as a function of growing season temperature …...............................................23

15 Yield in upland ecotypes as a function of growing season temperature ..........................24

16 Yield in lowland ecotypes as a function of growing season temperature ........................24

$17 \quad$ Boxplot of yield in upland ecotypes by precipitation and temperature ...........................27

18 Regressions through $95^{\text {th }}$ percentiles- upland …......................................................28

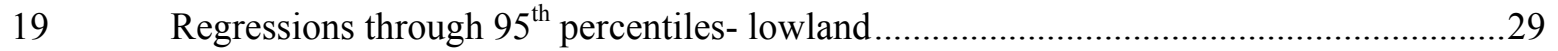

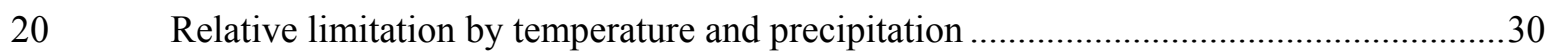

21 Predicted optimal yields in comparison to observed yields ......................................... 31

22 Predicted vs. observed in relation to temperature and precipitation..................................32 


\section{LIST OF MAPS}

Map

Page

$1 \quad$ Original range of switchgrass in North America ........................................................2

$2 \quad$ U.S. historical climatology network weather stations, and field site locations ..................7

3 Location of field sites indicating relative contribution of regions to data set ...................8

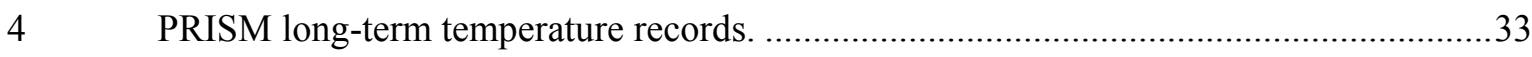

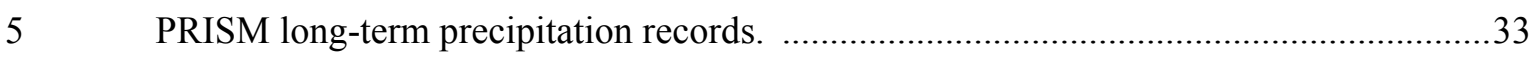

5 Projections of optimal switchgrass yields for lowland cultivars ....................................35

$6 \quad$ Projections of optimal switchgrass yields for upland cultivars .........................................36

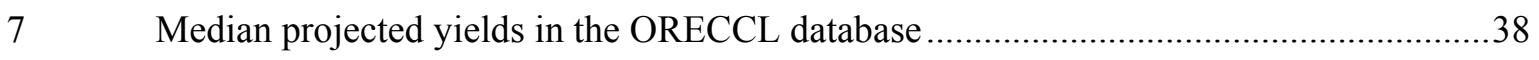




\section{LIST OF TABLES AND PLATES}

Table

Page

$1 \quad$ References contributing data to the analyses and modeling ........................................6

Plate Page

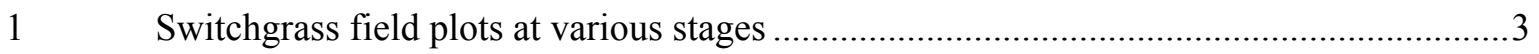

\section{ACKNOWLEDGEMENTS}

Research sponsored by the U.S. Department of Energy - Office of Energy Efficiency and Renewable Energy, Biomass Program. UT Battelle, LLC manages the Oak Ridge National Laboratory for the U.S. Department of Energy under contract DE-05-00OR22725 with UTBattelle, LLC.

The authors wish to thank many researchers who provided additional information and data for the analyses presented. Thanks also to Lynn Wright for providing access to and assistance with data and photographs, and for review of the manuscript. Portions of this work were derived directly from the thesis research of Ethan Davis at Aalborg University in Denmark. 


\begin{abstract}
In response to concerns about oil dependency and the contributions of fossil fuel use to climatic change, the U.S. Department of Energy has begun a research initiative to make $20 \%$ of motor fuels biofuel based in 10 years, and make $30 \%$ of fuels bio-based by 2030 . Fundamental to this objective is developing an understanding of feedstock dynamics of crops suitable for cellulosic ethanol production. This report focuses on switchgrass, reviewing the existing literature from field trials across the United States, and compiling it for the first time into a single database. Data available from the literature included cultivar and crop management information, and location of the field trial. For each location we determined latitude and longitude, and used this information to add temperature and precipitation records from the nearest weather station. Within this broad database we were able to identify the major sources of variation in biomass yield, and to characterize dry matter yield as a function of some of the more influential factors, e.g., stand age, ecotype, precipitation and temperature in the year of harvest, site latitude, and fertilization regime.
\end{abstract}

We then used a modeling approach, based chiefly on climatic factors and ecotype, to predict potential dry matter yields for a given temperature and weather pattern (based on $95^{\text {th }}$ percentile response curves), assuming the choice of optimal cultivars and harvest schedules. For upland ecotype varieties, potential yields were as high as 18 to $20 \mathrm{Mg}$ dry mass/ha, given ideal growing conditions, whereas yields in lowland ecotype varieties could reach 23 to $27 \mathrm{Mg} / \mathrm{ha}$. The predictive equations were used to produce maps of potential yield across the continental United States, based on precipitation and temperature in the long term climate record, using the Parameter-elevation Regressions on Independent Slopes Model (PRISM) in a Geographic Information System (GIS). Potential yields calculated via this characterization were subsequently compared to the Oak Ridge Energy Crop County Level data base (ORECCL), which was created at Oak Ridge National Laboratory (Graham et al. 1996) to predict biofuel crop yields at the county level within a limited geographic area.

Mapped output using the model was relatively consistent with known switchgrass distribution. It correctly showed higher yields for lowland switchgrass when compared with upland varieties at most locations. Projections for the most northern parts of the range suggest comparable yields for the two ecotypes, but because there were few field trials growing lowland ecotypes at high latitudes it is difficult to fully assess that projection. The final model is a predictor of optimal dry matter yields for a given climate scenario, but does not attempt to identify or account for other limiting or interacting factors. The statistical model is nevertheless an improvement over historical efforts, in that it is based on quantifiable climatic differences, and it can be used to extrapolate beyond the historic range of switchgrass. Additional refinement of the current statistical model, or the use of a different empirical or process-based model, might improve the prediction of switchgrass yields with respect to climate and interactions with cultivar and management practices, assisting growers in choosing high-yielding cultivars within the context of local environmental growing conditions. 


\section{INTRODUCTION}

The United States holds $3 \%$ of the world's petroleum reserves, yet consumes $25 \%$ of the world's annual petroleum production (U.S. DOE 2006, EIA 2006a). As a result, the U.S. imported 60\% of its oil in 2006, spending \$291 billion dollars on oil and oil related imports, which accounted for about one third of our total trade deficit. In response to concerns about cost, dependency on foreign sources, and rising demand, searching for feasible alternatives to oil has become a national priority. Nearly $70 \%$ of all oil consumed in the U.S. is used to supply the transportation sector; and $45 \%$ of all consumed oil is used to make gasoline. Finding alternative fuels and reducing transportation sector demand would have an immediately dramatic impact on oil consumption (EIA 2006b). Although there are longer-term solutions that hold tremendous potential (e.g. hydrogen fuel cells), one of the most immediately promising substitutes for petroleum-based fuels is the development of biofuels such as ethanol and biodiesel.

Accordingly, the Energy Policy Act (2005) signed by President George W. Bush calls for 7.5 billion gallons of ethanol to enter the supply by 2012; which would guarantee that approximately $5 \%$ of the nation's fuel is biobased (Moreira 2005).

As part of the Federal government's Advanced Energy Initiative, the United States Department of Energy (DOE) has announced an initiative to increase that proportion, so that biofuels will replace $30 \%$ of the nation's transportation fuels by 2030. Dubbed the 30-30 Initiative, a recent report entitled, Breaking the Biological Barriers to Cellulosic Ethanol (U.S. DOE 2006) highlighted key aspects regarding feedstocks, conversion, infrastructure and end-use technologies related to having cellulosic ethanol become the dominant fuel of the 30-30 Initiative. The report developed a technical strategy or roadmap to achieve the 30-30 Initiative consisting of three phases:

- Phase 1-Research: “...within 5 years an understanding of existing feedstocks must be gained to devise sustainable, effective, and economical methods for their harvest, deconstruction and conversion to ethanol. Research is centered on the enzymatic breakdown of cellulosic biomass to component 5-pentose and 6-hexose sugars and lignin (pentose and hexose) using a combination of thermochemical and biological processes followed by co fermentation of sugars to specified end products such as ethanol."

- Phase 2-Technology Deployment: “...within 10 years, will include creation of a new generation of energy crops with enhanced sustainability, yield and composition, coupled with processes for the simultaneous breakdown of biomass to sugars and co fermentation of sugars via new biological systems."

- Phase 3-Systems Integration: “...within 15 years, will incorporate concurrently engineered energy crops and biorefineries tailored for specific agroecosystems. Employing new and improved enzymes for breaking biomass down to sugars as well as robust fermentation processes jointly consolidated into plants or microbes, these highly integrated systems will accelerate and simplify the end-to-end production of fuel ethanol...approaching theoretical conversion limits" (DOE 2006). 
Moreover, in the 2007 State of the Union speech, President Bush announced the ambitious " 20 in 10 " initiative that calls for reducing gasoline demand $20 \%$ in 10 years by producing 35 billion gallons of ethanol (which would replace roughly $15 \%$ of gasoline), and improving the Corporate Average Fuel Economy (CAFE) standards to reduce demand by 8.5 billion gallons of gasoline, or $5 \%$ of the current demand (http://www.whitehouse.gov/stateoftheunion/2007/initiatives/energy.html).

The Biofuels Feedstock Development Program (BFDP) at ORNL was created in 1978 by DOE to identify and develop fast growing trees and herbaceous crops, and to evaluate crop residues as potential sources for fuel and power (Ferrell et al. 1995). Approximately 34 herbaceous species were screened at 31 sites across the United States, and on a wide range of soil types. Eventually, switchgrass (Panicum virgatum) emerged as a leading candidate for further study and development as a dedicated bioenergy crop, in part because it is widely adapted, with a high yield potential even on relatively poor quality sites (Wright, 2007).

In order to reach the biofuel production goals, more information is needed to characterize potential production rates of these bioenergy crops in relation to soil, climate, and cultivation practices. ORNL has begun a new project examining productivity of switchgrass and of woody plants as a function of local resources and conditions. Bioenergy crop yields, as well as supply logistics will be considered in order to more accurately determine the quantity, location, and associated costs of producing cellulosic ethanol derived from biofuels.

This report focuses on the genetic, climatic, edaphic, and crop management factors that may influence yield in switchgrass. Subsequent work will incorporate yield predictions into models with economic and logistic considerations which are outside the scope of this report.

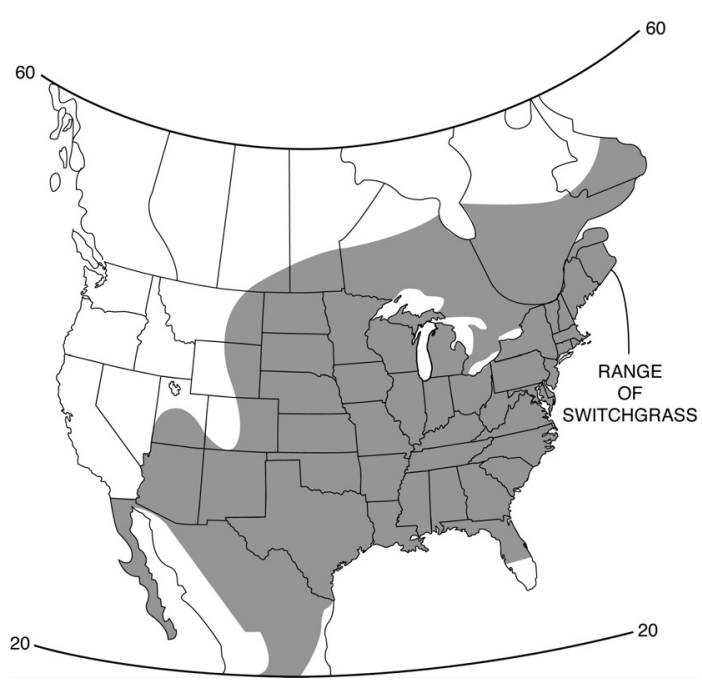

Map 1. Distribution of switchgrass, Panicum virgatum L. ORNL-DWG 94M-9566, after Stubbendieck et al. (1992).

\section{Switchgrass}

Switchgrass, Panicum virgatum L., is a warmseason perennial, native to North America (Plate 1); it was historically an important part of the highly productive North American tallgrass prairie. Ranging from Mexico to Quebec (Map 1), the species as a whole tolerates a wide variety of growing conditions, ranging from arid sites in the shortgrass prairie to brackish marshes and open woods. Across the distribution are two genetically and phenotypically distinct forms or ecotypes, a lowland type generally found in wetter, and more southern habitats, and an upland form typically found in drier mid- and northern latitudes (Porter 1966, Sanderson et al. 1996, 
Hultquist et al. 1997, Casler et al. 2004). Lowland ecotypes tend to occur in river bottoms, are tall, thicker stemmed, vigorous, and have bunch growth habits, whereas upland ecotypes are shorter, rhizomatous and fine-stemmed (Porter 1966, Sladden et al. 1991).

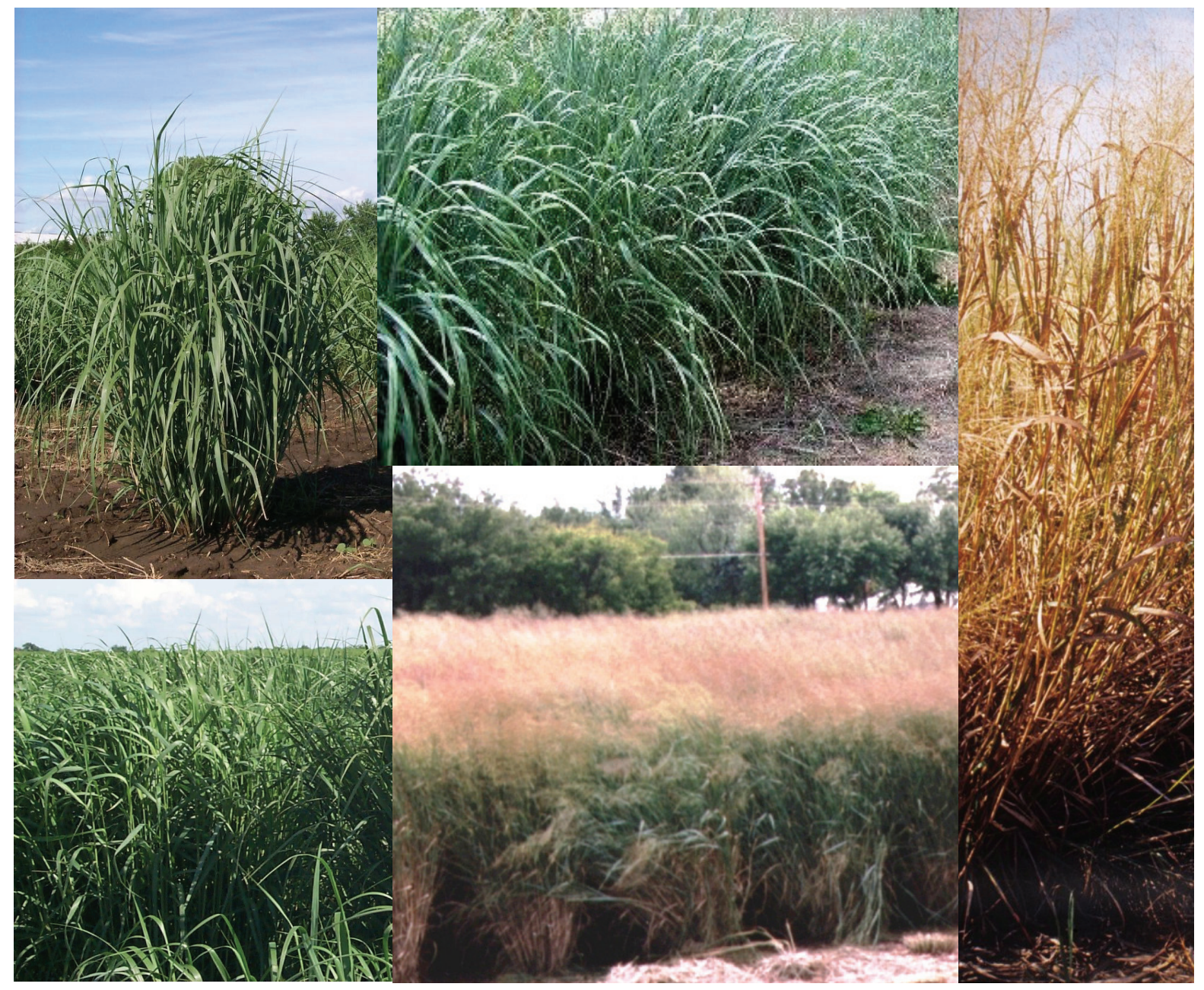

Plate 1. Switchgrass in the field. Clockwise from upper left, nursery plot showing bunch habit of a single plant, demonstration plot before flowering, field ready to harvest, switchgrass at flowering, large field plot. Photos courtesy Oak Ridge National Laboratory.

Variation within an ecotype, e.g., in reproductive phenology and winter-hardiness, appears related to latitude of origin; more southern cultivars tend to flower later in the season, allowing more time for vegetative growth and therefore increasing yields. The lower winter-hardiness of lowland strains, however, may result in low winter-survival when grown too far north (Parrish and Fike 2005). Productivity of upland ecotypes tends to exceed that of lowland ecotypes at very high latitudes, and be reduced at southern locations, yet yields from upland strains adapted to relatively more southern locations may be sustained at low latitudes (Casler et al. 2004). Similarly, yield and winter survival declines at high latitude sites, more so for strains of more southern origin, whether of lowland (Casler et al. 2004) or upland morphology (Berdahl et al. 2005). Responses 
to precipitation are ambiguous; some research has found that yields were not strongly correlated with precipitation inputs (Cassida et al. 2005b), whereas many investigators have found positive correlations between precipitation and yield, with sensitivity to soil moisture differing between ecotypes (Berdahl et al. 2005, Cassida et al. 2005b, Lee and Boe 2005, Fike et al. 2006a and b). The high degree of phenotypic and ecotypic variation is not surprising, given the cytotypic diversity within switchgrass. Lowland switchgrass ecotypes are predominately tetraploid, with a base chromosome number of 9 (diploid number 18), leading to 36 chromosomes $(2 n=4 x=36)$. Upland ecotypes are even more diverse, exhibiting octoploidy $(2 \mathrm{n}=8 \mathrm{x}=72)$ and less commonly, hexaploidy $(2 \mathrm{n}=6 \mathrm{x}=54)$ (Gunter et al. 1996, Hopkins et al. 1996). For a more complete discussion of switchgrass biology and agronomic issues, see the excellent review of Parrish and Fike (2005). Additional information on the natural history and physiology of switchgrass, and why these crops were originally selected, see Wright (2007).

\section{Previous yield estimates}

The first comprehensive database that estimated geographically-explicit yields and probable farmgate prices for bioenergy crop production was the Oak Ridge Energy Crop County Level (ORECCL) Database (Graham et al. 1996, 1997). The database provided estimates of the median expected yields for switchgrass and short-rotation woody crops for all U.S. counties in regions deemed suitable for the crop in question, as well as high (optimistic) and low (pessimistic) yield estimates, which were designed to encompass yields for $50 \%$ of the land in the region, with $25 \%$ of the land achieving higher and lower yields. The database was created when field trials for bioenergy crops were not available for all regions, and it relied on expert opinion as well as published yield values, research trials, and existing yield models when available. Estimates assumed best management practices at that time, and for switchgrass, were limited to existing cropland. No differentiations were made with respect to ecotype, and the model did not make predictions for areas outside the native range, though it has now been successfully cultivated in other regions, e.g., the Pacific Northwest (Fransen et al. 2006). The focus of this research is therefore improving our ability to estimate switchgrass productivity across the U.S., based on a more theoretical understanding of the relationships of yield to genetic, climatic, resource, and management factors.

\section{OBJECTIVES AND APPROACH}

The first objective of this project was to compile, for the first time, a database from published switchgrass field trials, including not only yield data for cultivars and ecotypes, but also information on the timing and location of the studies and the associated soil, temperature, precipitation, and resource variables. The intention was to examine the relationship between yield and those variables, first through visual inspection of plots of the relationships. The next objective was to explore a regression-based modeling approach, based on those relationships, to describe switchgrass yield as a function of key variables, potentially including ecotype, environmental resources and weather conditions, management regimes (e.g., cut frequency, stand age, row spacing, and fertilization), etc. in an attempt to explain the variability in reported yield. The 
regression model would then be validated using a subset of the data. The final objective was to use the yield model, in combination with GIS layers representing 30-year average climate data, to

provide a spatially explicit projection of potential switchgrass yields across the continental United States.

\section{Data Selection and Site Characterization}

The initial step in the process was a literature survey of peer-reviewed, open-literature primary sources that reported switchgrass yield values for an individual year, site, and treatment, with an emphasis on studies that focused on bioenergy production in the United States. Yield data were compiled only from field trials, extracting data from text, tables and graphs, and were converted to $\mathrm{Mg}$ (dry mass)/ha if necessary. These data were compiled with reference to the location of each field site, taking advantage of the broad range of temperature and precipitation patterns across the many sites and harvest years represented. A total of 30 papers reporting unduplicated field data were identified, although not all papers included data summarized by site and by year, but instead published yields averaged across multiple years or multiple sites. In some cases, authors provided the missing data via personal communication. When these detailed yield data were not available, the papers were excluded from the regression analyses, leaving 16 papers with approximately 1,400 observations (Table 1).

For each site, environmental resources and management regimes were characterized, either from the papers, or by personal communication with the authors. Latitude and longitude for each site were determined, which enabled the use of nearest weather station data, since weather data were not provided in all papers. Weather data from the U.S. Historical Climatology Network were then mapped and matched to field sites. The Network provides data for 1,221 collection stations reporting climate data until 2006 (red dots on Map 2). Locations of these stations were used in a Geographical Information System (GIS) analysis to locate the nearest weather station to each study site (bright red dots with black centers) and locations were overlaid on Map 2 using ESRI ArcInfo and ArcMap 9.2. After determining the closest weather station, a SAS program was written to extract monthly and annual climate data corresponding to the harvest year at a given field trial site. This method allowed us to use yield values from any site, although actual values collected at a field site.

Assigning latitude and longitude values to the sites also facilitated the determination of broad classifications of soil textures. The primary classification used was from http://www.soilinfo.psu.edu/index.cgi?soil data\&conus\&data cov\&fract\&methods. If no texture description was given, then a query was run at: http://ssldata.nrcs.usda.gov/querypage.asp. If the soil characterization was not compatible with soils triangle descriptions (silt, sand, clay), then this document was searched: http://soils.usda.gov/technical/classification/tax keys/keys.pdf. 
Table 1. References contributing data to the univariate analyses (Figures 5-15) and to the model.

\begin{tabular}{lccc}
\multicolumn{1}{c}{ Reference } & $\begin{array}{c}\text { Reference } \\
\text { ID* }\end{array}$ & $\begin{array}{c}\text { Number of } \\
\text { observations }\end{array}$ & $\begin{array}{c}\text { Number of } \\
\text { locations }\end{array}$ \\
\hline Berdahl et al., 2005 & $\mathbf{1}$ & 72 & 2 \\
Bouton, 2002 & $\mathbf{4}$ & 60 & 2 \\
Casler \& Boe, 2003 & $\mathbf{2 4}$ & 48 & 2 \\
Casler et al., 2004 ${ }^{\dagger \dagger}$ & $\mathbf{6}$ & 20 & 5 \\
Cassida et al., 2005a & $\mathbf{8}$ & 32 & 4 \\
Fike et al., 2006a & $\mathbf{9}$ & 192 & 7 \\
Fuentes et al., 2002 & $\mathbf{1 0}$ & 154 & 2 \\
Kiniry et al., 1996 & $\mathbf{1 2}$ & 18 & 6 \\
Kiniry, Tischler \& Van Esbroeck, 1999 & $\mathbf{2 5}$ & 19 & 1 \\
Lemus et al., 2002 & $\mathbf{1 4}$ & 60 & 1 \\
Lemus, 2004 & $\mathbf{1 3}$ & 128 & 7 \\
Muir et al., 2001 & $\mathbf{2 2}$ & 45 & 2 \\
Sanderson, Read \& Reed, 1999a & $\mathbf{1 7}$ & 71 & 5 \\
Sanderson et al., 1999b & $\mathbf{1 6}$ & 233 & 1 \\
Sanderson et al., 2004 & $\mathbf{2 9}$ & 10 & 1 \\
Sladden, Bransby \& Aiken, 1991 & $\mathbf{2}$ & 89 & 2 \\
Thomason et al., 2004 & $\mathbf{1 8}$ & 133 &
\end{tabular}

* Reference ID refers to identification number in the database.

${ }^{\dagger}$ Location refers to the geographic designation used by the author for a site (or group of colocated sites), and to a unique latitude-longitude combination.

${ }^{\dagger}$ Casler et al., 2004 contained only 2-year yield averages; used for latitudinal plots only. 


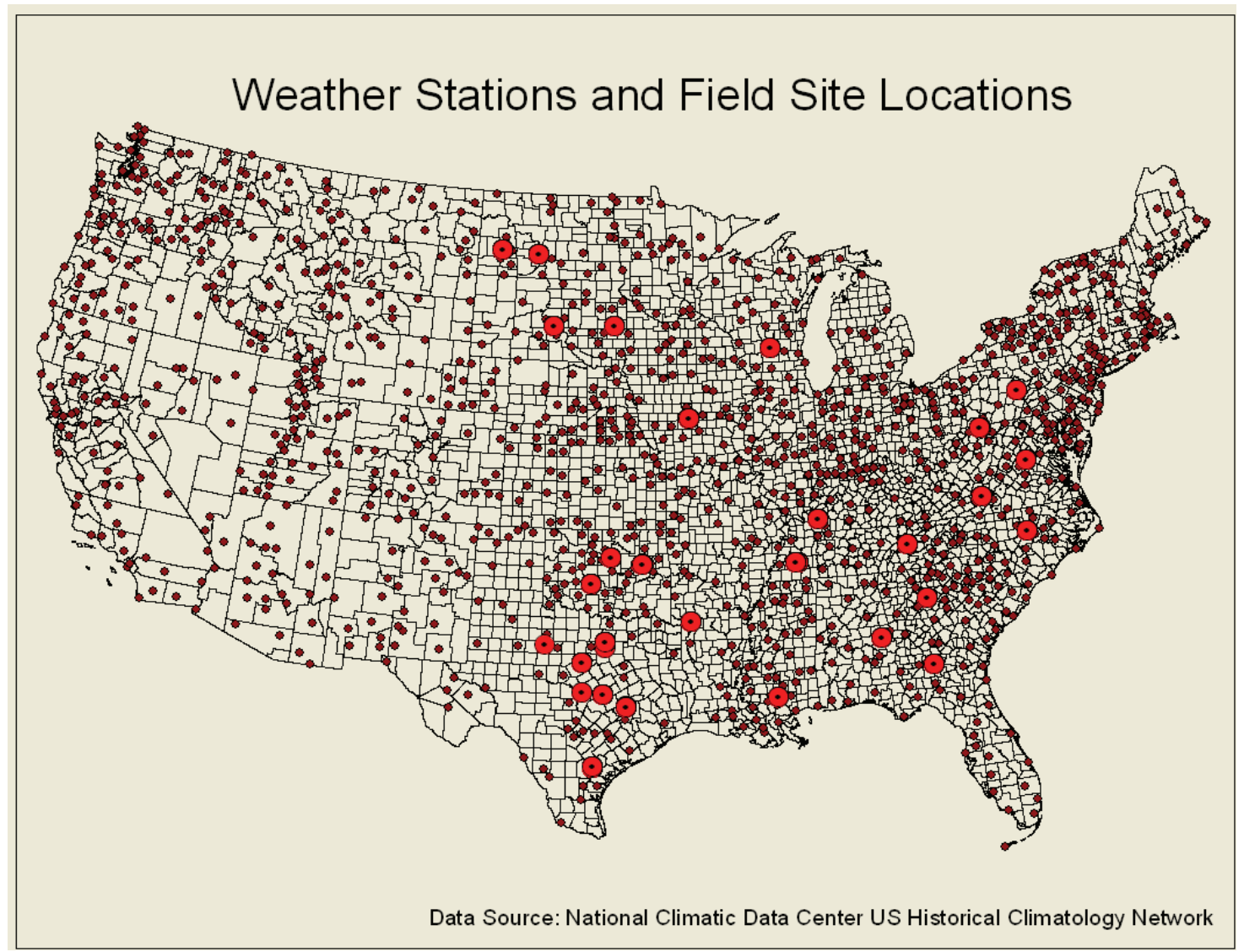

Map 2. U.S. Historical Climatology Network Weather Stations and Field Site Locations.

After adding the weather and soils data as described, each of the 1,408 data points was associated with a total of 21 fields that described the following influences on yield:

Spatial: site number, site location (latitude and longitude);

Plant type: ecotype (upland or lowland), cultivar;

Management: year planted, year harvested, age of stand, plot size, row spacing, fertilizer amount, fertilizer application rate, number of harvests, irrigation;

Environmental: annual precipitation, growing season precipitation, annual temperature, $\%$ sand, $\%$ silt, $\%$ clay, and other.

The spatial results of the data compilation are shown in Map 3, where each red dot indicates a unique research site, giving a total of 31 different locations for field trial yield data. Location data are overlaid with MODIS satellite imagery data of Land Cover (http://edcdaac.usgs.gov/modis/dataproducts.asp).

As indicated in Maps 2 and 3, data were drawn from field sites widely distributed across the southeast, south central, north central, and mid-Atlantic states. Sites ranged from $28^{\circ}$ to $47^{\circ} \mathrm{N}$ latitude and from nearly $75^{\circ}$ to $105^{\circ} \mathrm{W}$ longitude. A comparison with Map 1 also illustrates that 
the field trials represent most areas of the native distribution of switchgrass in the U.S. (east of the Rocky Mountains, from Mexico to Quebec).

In addition to the broad geographic range covered by the published switchgrass yield data, Map 3 also indicates the relative contribution of each location to the overall data set. The size of the red circles indicates the relative number of data points that are accounted for by each study site.

Although there were large pools of data from Texas and Oklahoma, Map 3 shows an otherwise relatively even distribution of data points within the covered geographic area. No one region was disproportionately influencing the inputs used in the analyses or exerting undue influence on the models relative to other regions.

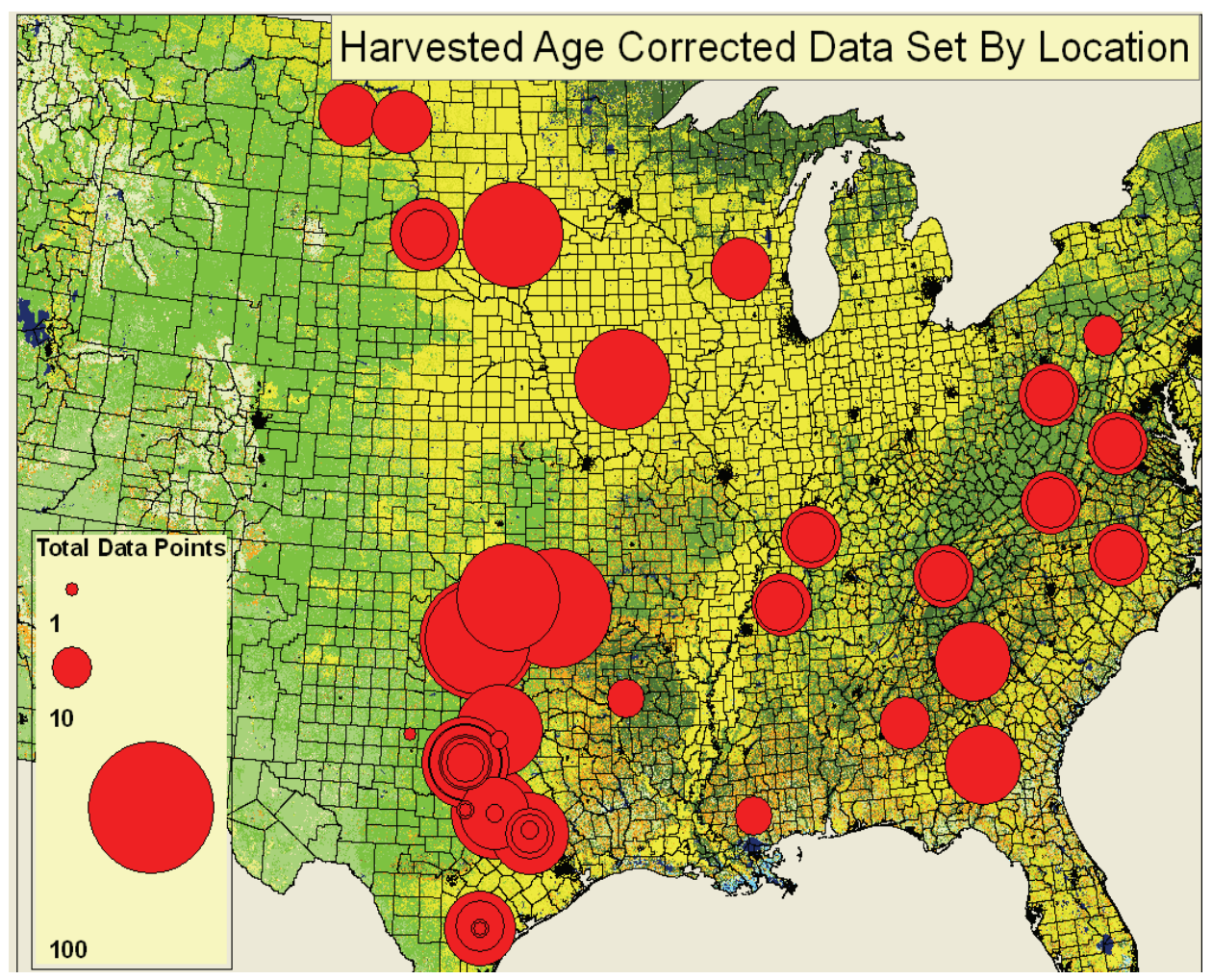

Map 3. Location of field sites indicating relative contribution to data set. Background color indicates MODIS land cover types. 


\section{PRELIMINARY DATA ANALYSES}

Across the full data set generated by the literature survey, switchgrass yield estimates varied considerably-- from less than $1 \mathrm{Mg} / \mathrm{ha}$ to almost $40 \mathrm{Mg} / \mathrm{ha}$. All yield data are expressed on a dry mass basis in this report. As indicated by a histogram of the data distribution (Figure 1), the most frequently observed yield class across all ecotypes, cultivars, soils, and management practices was between 10 and $12 \mathrm{Mg} / \mathrm{ha}$. The frequency distribution of yield was unimodal, and skewed to the left, with a long tail at higher yields. Very few experimental stands had yields lower than 2 or higher than $28 \mathrm{Mg} / \mathrm{ha}$. In an attempt to understand the sources of this variability, the first exploratory plots were of variables known to influence yield.

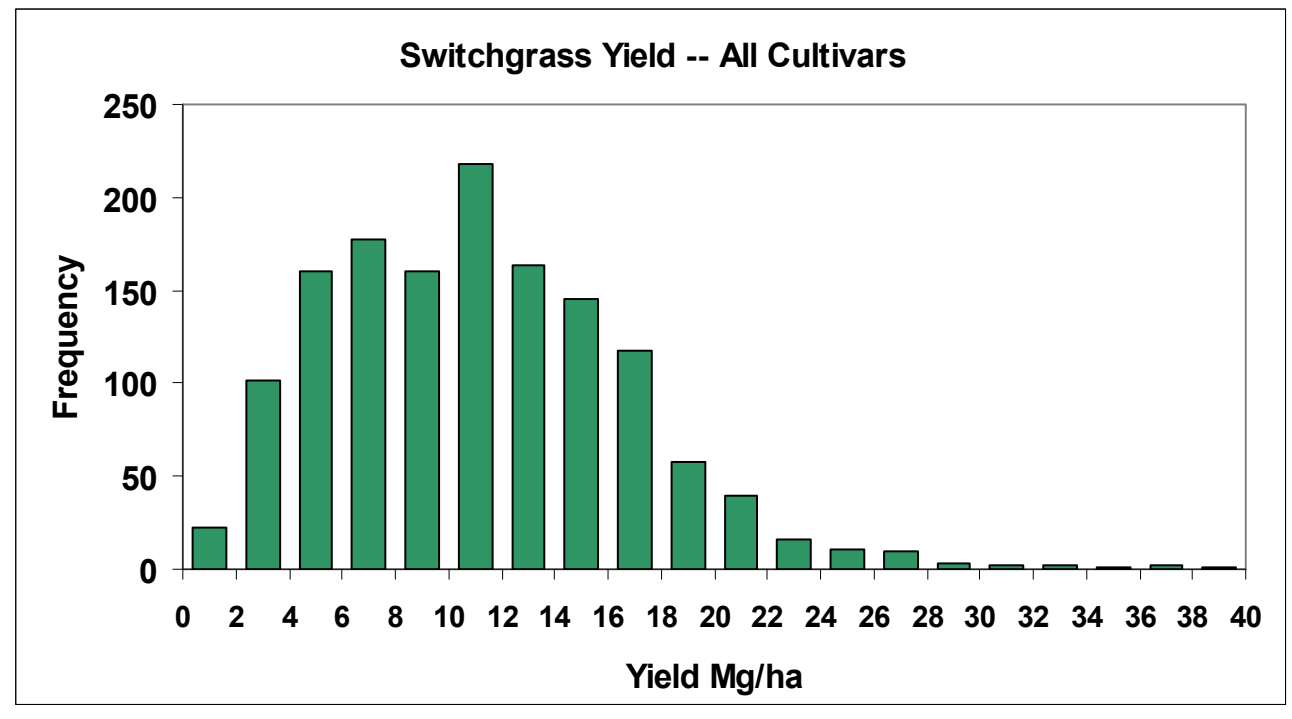

Fig. 1. Frequency distribution of switchgrass dry mass yields.

Switchgrass is a perennial that usually takes at least one growing season to become established from seed, and does not reach full maturity until year two or three (Parrish and Fike 2005). Furthermore, cultivars of the lowland ecotype typically produce a larger quantity of aboveground biomass than do upland cultivars, notwithstanding the strong genotype $\mathrm{x}$ environment interaction mentioned previously (Porter 1966, Sladden et al. 1991, Fuentes \& Taliaferro 2002, Casler et al. 2004). Consistent with those observations, harvests of one-year-old stands in this data compilation consistently yielded lower biomass in both upland and lowland ecotypes (Figure 2). Differences between upland and lowland ecotypes were also evident in each age category, and therefore ecotypes will continue to be considered separately in this analysis. Means do not represent the same number of data points, because studies varied in the numbers of years yield was measured (e.g., in some studies, yield was only measured in the early years, and in a few, only long-term yields were assessed. The apparent low yields at year five are therefore likely to be artifacts of unequal sample sizes across age classes and the reduced yields for stands 20 years or older could be the result of stand aging, or merely be related to the small sample size. Missing bars (e.g., lowland, years 20 and 21) indicate a complete lack of yield data in the category. 


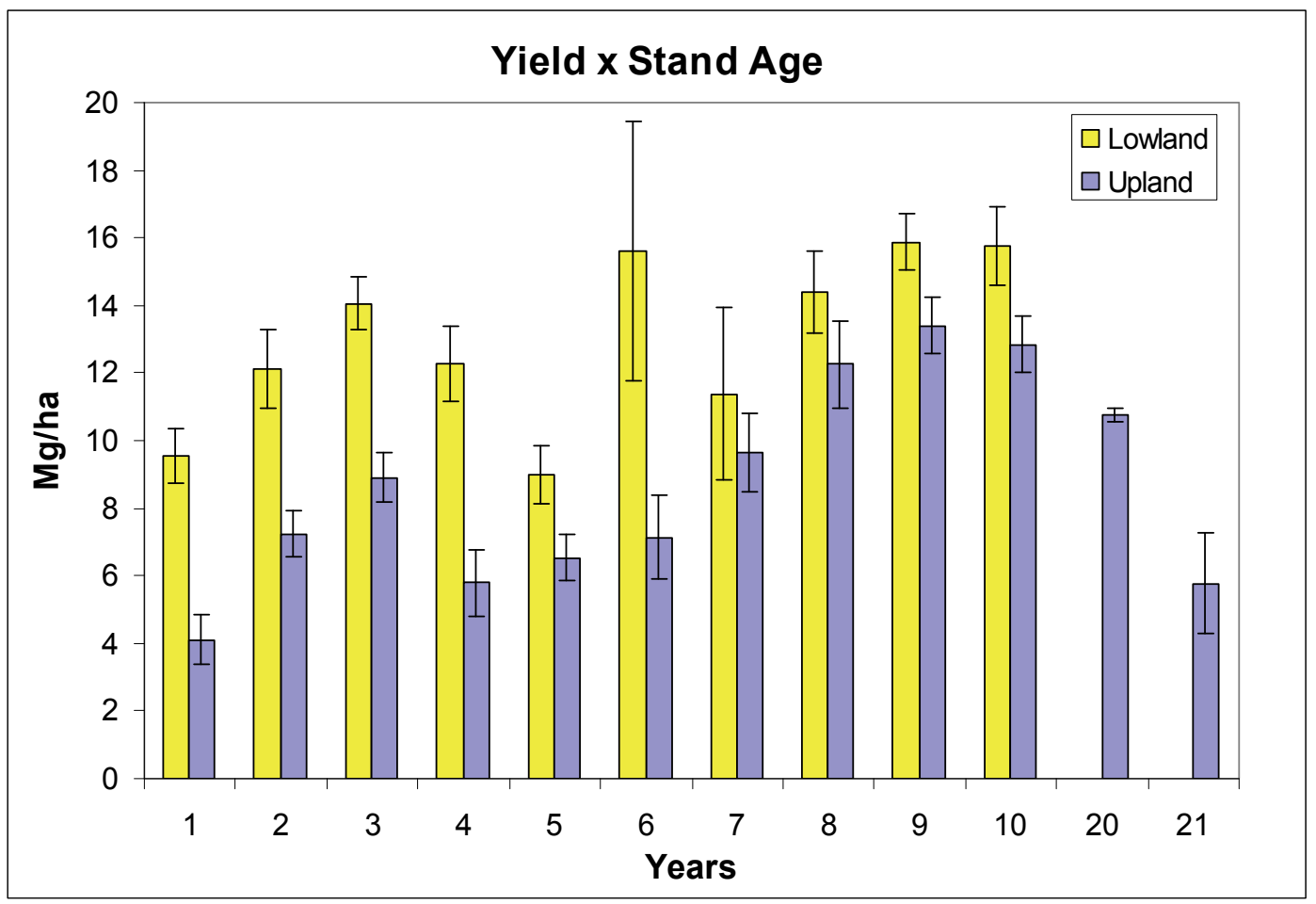

Fig. 2. Annual switchgrass yields, grouped by stand age at harvest, and by ecotype (yellow for lowland, blue for upland ecotype). Error bars represent the $95 \%$ confidence intervals around the means.

Switchgrass can also be harvested with a one-cut, or multiple-cut harvest system, referring to the number of times the crop is harvested within a growing season. Annual yields under a four-cut harvest system were significantly lower than yields under a one, two, or three-cut harvest system (Figure 3), consistent with the conclusions of Sanderson et al. (1999a). On average, four cuts per season reduced total yield by roughly one half. There were no studies of three-cut harvest systems in upland ecotypes.

\section{Data Exclusions}

The objective of this research was to quantify the yields of mature switchgrass stands, and to associate variability in yield with variation in quantifiable independent variables, e.g., climate, soils, and management practices. Initial observations (Figures $\mathbf{2}$ and $\mathbf{3}$ ) confirmed the known association of low yields with first-year stands and four-cut harvest systems. Yield data from first-year harvest and four-cut systems were therefore dropped from the regression analyses, to better relate yield to variables of interest, i.e., plant type (genetics), climate and soil variables (environment), and other management practices. When preparing the data set for exploratory regressions of yield as a function of the remaining variables, a conscious decision was also made 
to drop observations with yields less than $1 \mathrm{Mg} / \mathrm{ha}$, assuming that such low yields could be attributed to poor initial stand establishment, or to management difficulties, (e.g, weed competition, unfavorable weather interfering with planting or harvesting), and that including them would have biased the data analysis. These exclusions reduced the data set from 1,408 to 1,291 data points, coming from 16 references. The mean yield across the remaining data was 11.6 $\mathrm{Mg} / \mathrm{ha}( \pm 5.7)$. The embedded title of Map 3 (Harvest Age Corrected) thus refers to the data remaining after eliminating the observations associated with four harvests per year or with the first (establishment) year for a stand.

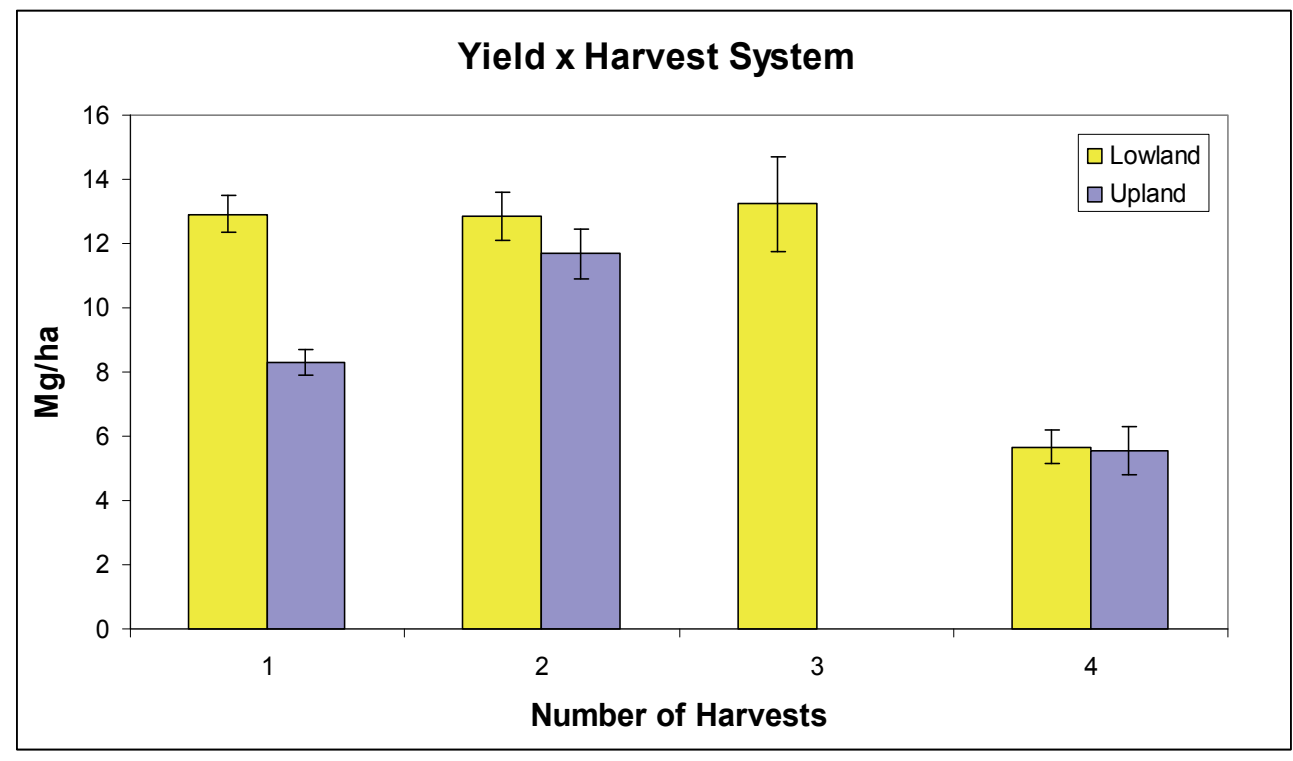

Fig. 3. Annual yield for lowland (yellow) and upland (blue) ecotypes, grouped by the number of times per year the plots were cut. Error bars represent the $95 \%$ confidence intervals around the means.

In Figures 2 and 3, large differences between the two ecotypes were observed within each category; lowland ecotypes had noticeably higher yields than upland types in each stand age category, and each harvest system, with the exception of the four-cut system, where differences were small.

The next sources of variability examined were therefore ecotype and cultivar within ecotype (Figure 4). Yellow, blue, and striped bars indicate whether the stand consisted of lowland, upland, or mixed cultivar(s), respectively. As before, error bars indicate the $+/-95 \%$ confidence interval associated with each mean.

Figure 4 reflects the observation that lowland cultivars, on average, yielded more than the upland cultivars (13.11 vs. $9.30 \mathrm{Mg} / \mathrm{ha}$ ). The differences among the ecotypes (upland and lowland, or upland, lowland and mixed) were highly significant ( $\mathrm{P}<0.001$, PROC GLM, SAS, SAS Institute, Cary, NC), despite the considerable variation in yield seen within an ecotype (Fig. 4). There was more than a two-fold difference in average yield within each group; yields ranged from $5-11$ 
$\mathrm{Mg} /$ ha for upland and from $8-16 \mathrm{Mg}$ /ha for lowland ecotypes. The variability was such that some of the higher-performing upland cultivars outperformed, on average, the lower-yielding lowland cultivars.

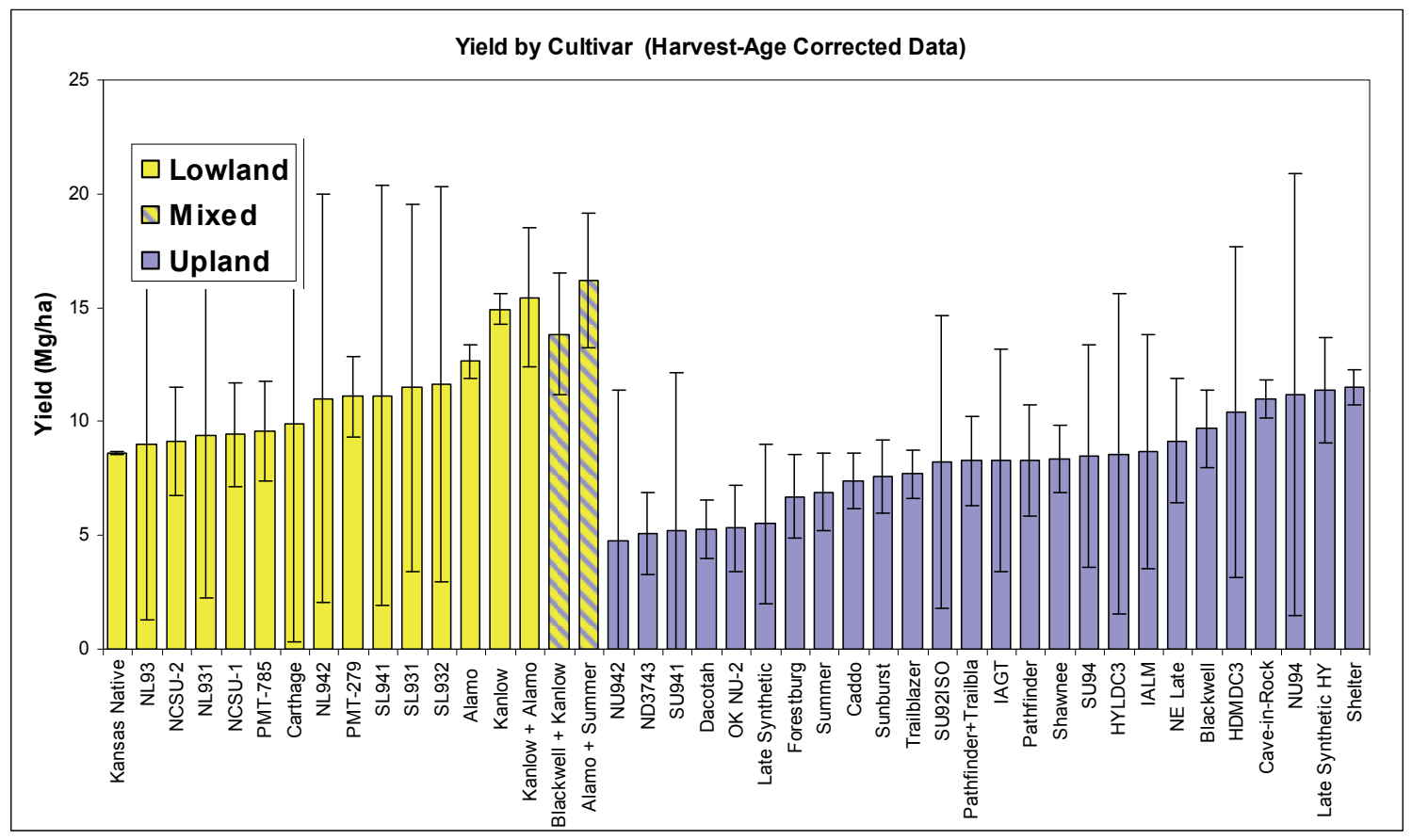

Fig. 4. Mean dry matter yield by cultivar. Cultivars are grouped by ecotypes, indicated by bars colored yellow (lowland), blue (upland), or striped (mixed ecotypes).

Within the lowland ecotype, Alamo and Kanlow were the highest yielding cultivars. Among upland ecotypes, the experimental strain Late Synthetic HY, as well as Shelter, NU94, Cave-InRock, HDMDC3, and Blackwell were the highest yielding. It should be mentioned that, of the upland ecotypes, Cave-in-Rock had more data points associated with it (147), as compared to Shelter (94), Late Synthetic HY (14), NU94 (3), HDMDC3 (3) and Blackwell (23). Within the lowland ecotype cultivars, Alamo and Kanlow were extensively studied, and provided 232 and 231 data points respectively, whereas SL932, 931, and 941 provided only 4 observations each. The large error bars associated with some individual cultivars indicated a small number of data points (e.g., 2 to 4), more so than an unusually large range of yields.

A wide range of variation between and within ecotypes has been observed in many previous studies (e.g., Sanderson et al. 1999b, Lemus et al. 2002, Lemus 2004, Casler et al. 2004), yet annual yields for the more robust lowland form are generally higher, except at high latitudes (Sladden et al. 1991, Fuentes \& Taliaferro 2002, Casler et al. 2004). The different geographic origins of the two ecotypes, with lowland types generally originating across a more southern range, and upland varieties originating in drier or colder mid- and upper latitudes, and their differential responses to climate, suggest the possibility of environmental adaptations at the population or ecotype level (Casler et al. 2004). The differences between lowland and upland 
ecotypes were therefore sufficient to prompt separate analyses for the two ecotypes, and the development of yield models using regressions specific to each ecotype.

\section{UNIVARIATE ANALYSES}

After limiting the scope of the data to mature stands with three or fewer harvests, and partitioning by ecotype, the effect of location and climate on yield was examined one by one to identify major sources of variation. One factor contributing to the relative ranking of ecotypes in Figure 4 could be the locations of individual field trials. Significant interactions between location and cultivar are often reported for yield values (Hopkins et al. 1995, Fuentes and Taliaferro 2002, Casler and Boe, 2003). Casler et al. (2004) demonstrated, for example, that the latitude of the field trial had a marked influence on the relative performance of various cultivars, and therefore cultivar rankings. Some cultivars have been studied over a wide range of locations, e.g. Alamo, Kanlow, and Cavein-Rock; the former two because of interest in their relatively high potential yields, the latter because it was the cultivar selected for initial screening trials in DOE's Biofuels Feedstock Development Program (Wright 2007). As a result, cultivars were often planted outside the range (latitude or longitude) where they were expected to have the highest yields. Although upland cultivars were screened as far south as were lowland cultivars, only a few field trials of lowland (southern) cultivars were conducted in the upper latitudes. In cases where single year data were not available the observations were not included in the analyses, but 2-year means from the latitudinal transect of Casler et al. (2004) are shown for reference; they also represent means from multiple cultivars.

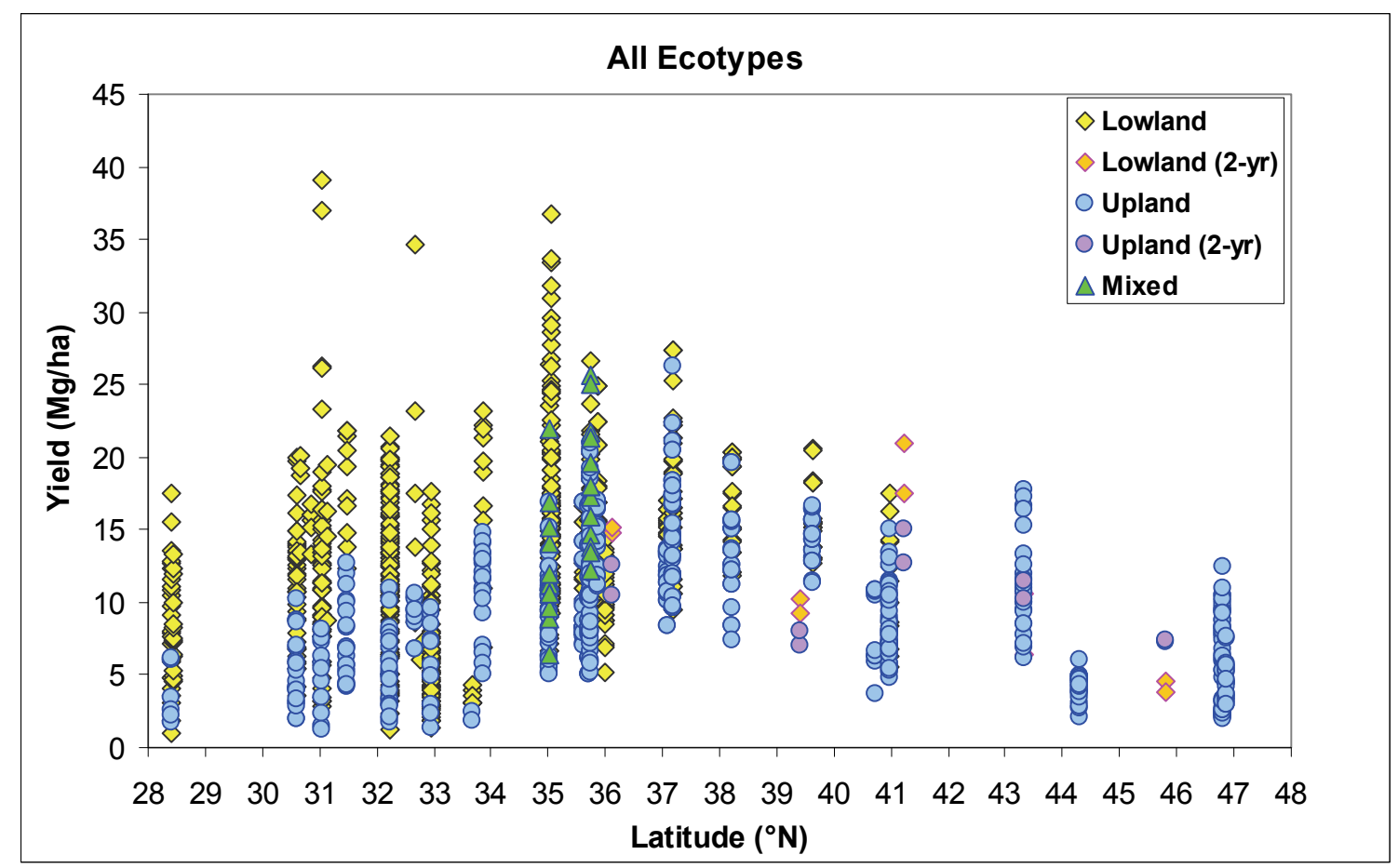

Fig. 5. Upland, lowland, and mixed stands as a function of latitude. Orange diamonds and lavender circles represent 2-year mean yields in a latitudinal study (Casler et al. 2004). 
The relationship between latitude and yield is shown in Figure 5 for all field trials, including lowland (yellow and orange diamonds), upland (blue and lavender circles), and mixed uplandlowland plots (green triangles). This plot reveals both similarities and differences in the relationship of latitude to yield for the two ecotypes. Taken together, switchgrass appears to have optimal yields between 35 and $40^{\circ} \mathrm{N}$. At lower latitudes $\left(28\right.$ to $\left.36^{\circ} \mathrm{N}\right)$, however, upland ecotypes performed noticeably more poorly than did the lowland cultivars. The mixed plots, representing two sites in a single study (Fuentes \& Taliaferro 2002), had intermediate yields, though closer to the overall yields of upland cultivars at those latitudes. (Throughout this document, graphs of "all ecotypes" will include data from the stands of mixed upland and lowland plants whether or not specific ecotypes are indicated.)

Within the lowland ecotypes alone (Figure 6) a relationship of yield to latitude was somewhat obscured by the wide range of yields at lower latitudes. Maximum yield generally increased between $28^{\circ}$ and $35^{\circ}$ to $37^{\circ} \mathrm{N}$ and decreased above $35^{\circ}$ or $37^{\circ} \mathrm{N}$. Similarly, minimum yield increased between $33^{\circ}$ and $38^{\circ}$ and declined above $38^{\circ}$ or $40^{\circ} \mathrm{N}$. As noted earlier, the only data from lowland varieties grown north of $41^{\circ}$ latitude available in this dataset were means from multiple lowland cultivars, (grouped into those with relatively northern vs. southern origins), averaged over a 2-year period; they are shown in orange. Those four means suggest that yields of lowland strains cultivated at high latitudes would decrease sharply, as they do in upland strains, to similar, or perhaps lower values (Figure 5).

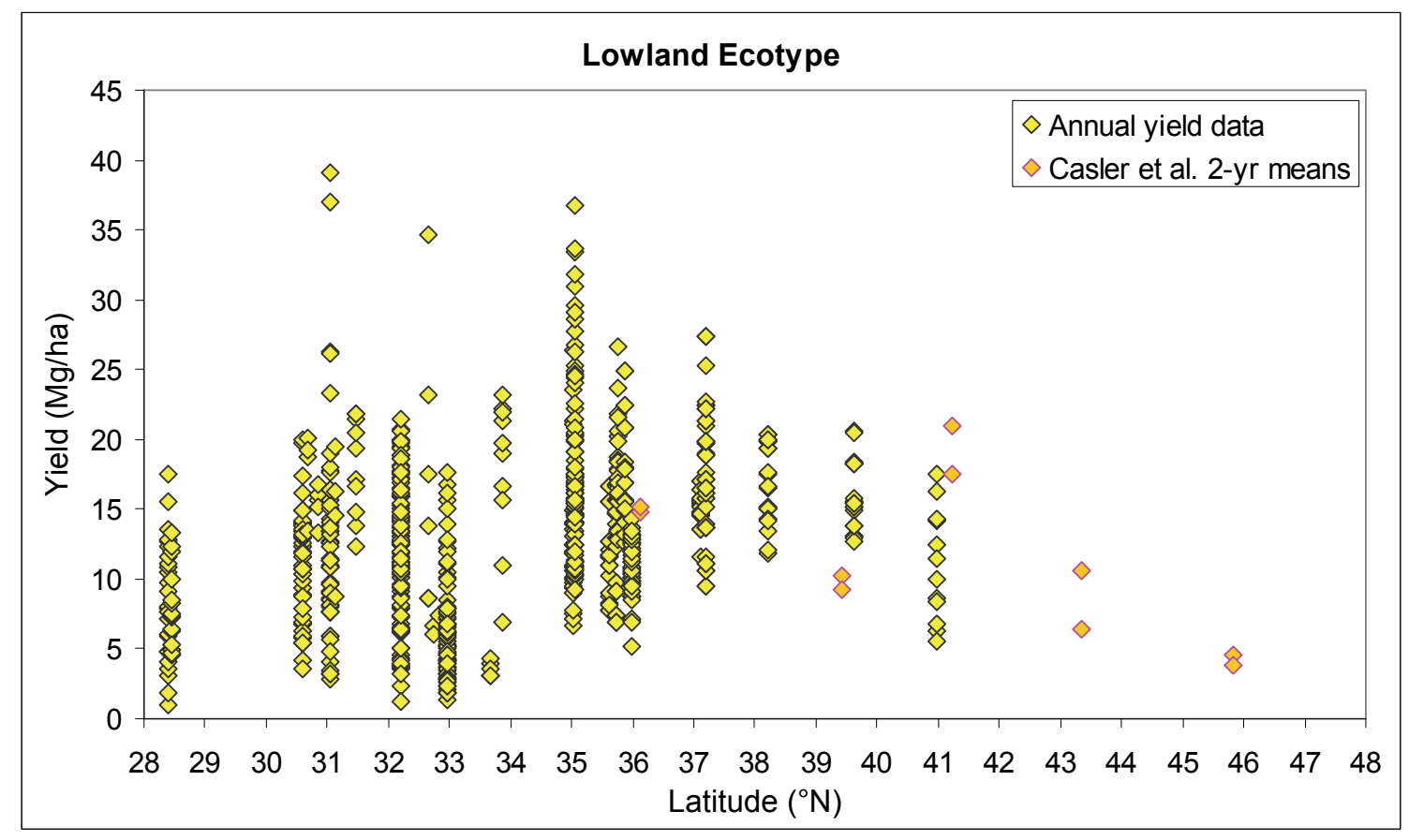

Fig. 6. Lowland ecotypes as a function of latitude. 
In the upland ecotypes (Figure 7), trials were planted from about $28^{\circ}$ to $47^{\circ} \mathrm{N}$. In the upland data, a fairly obvious relationship with latitude appeared, and an "optimum" latitude for yield emerged between approximately $36^{\circ}$ and $39^{\circ}$, below and above which both maximum and minimum yields were lower. Overall yields in the upland cultivars, however, never reached the yields from lowland plots growing at the optimal latitudes.

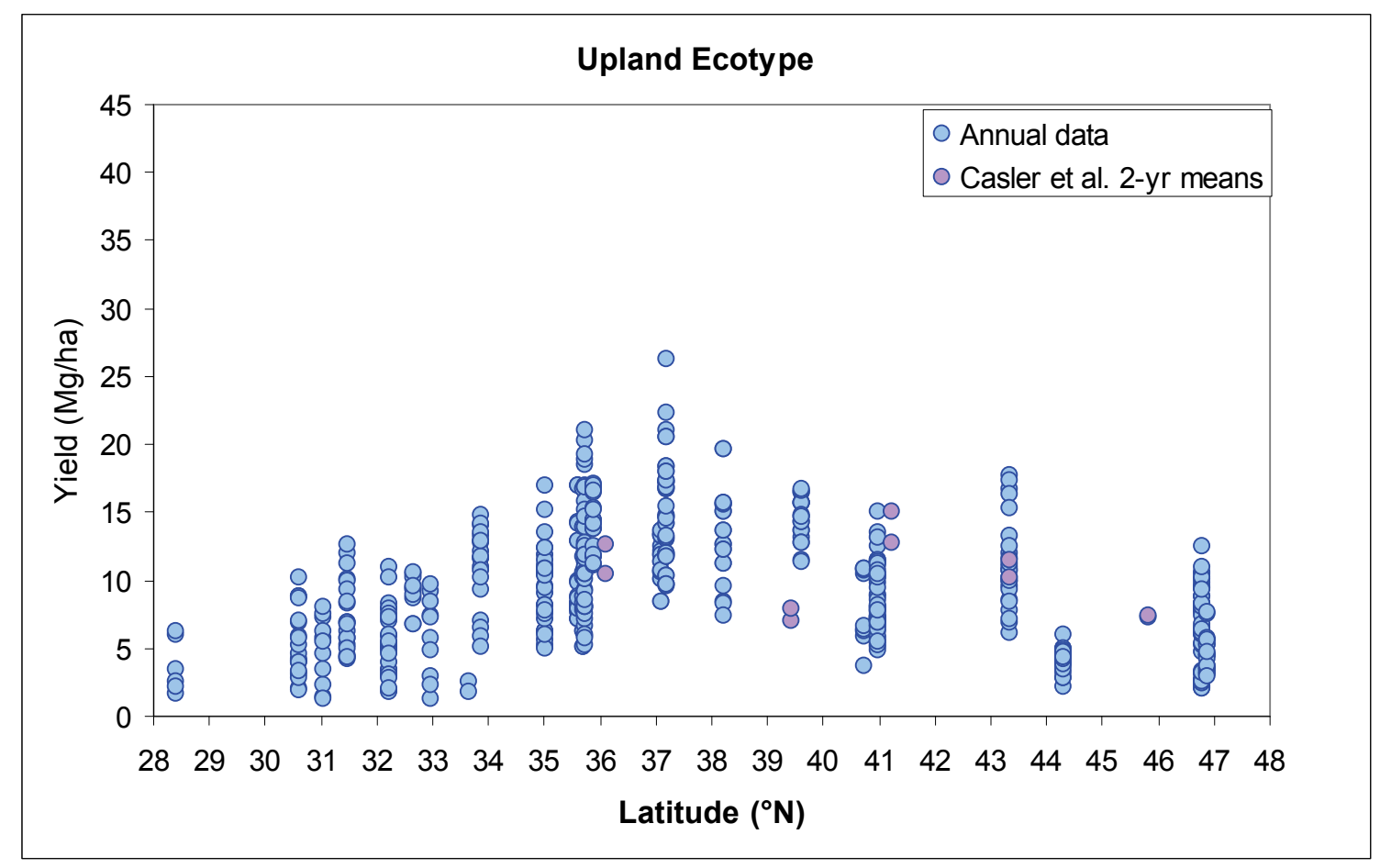

Fig. 7. Upland ecotypes as a function of latitude.

Although strong latitudinal patterns were observed, these data fail to establish absolute upper and lower bounds for biomass yield of either ecotype of switchgrass, although the yields of both morphologies decline at high latitudes (Casler et al. 2004, Berdahl et al. 2005) and winter survival may be problematic (Vogel et al. 2002). The reported range limit is $51^{\circ} \mathrm{N}$ (Jefferson et al. 2004, Parrish \& Fike 2005). Furthermore, even though there are latitudinal patterns for both minimum and maximum yield, the range of yields observed at each latitude is too broad for latitude alone to explain all of the variability in yield within or between ecotypes.

The noise in the yield-to-latitude relationships is not surprising, given that the compiled yield values are associated with different soils, different cultivars, and different regimes for fertilization, planting, weed control, and harvesting. Yields also represent different growing years, with inter-annually varying conditions, e.g., temperature, precipitation, solar radiation, and soil moisture availability. The highest yield, for example, $39.10 \mathrm{Mg} / \mathrm{ha}$, was obtained in a plot of the Alamo cultivar under heavy fertilization $(200 \mathrm{~kg} \mathrm{~N} / \mathrm{ha})$, in a year with relatively high precipitation and temperatures (Kiniry et al. 1999). 
Patterns of yield in relation to longitude in these data (Figure 8) were weak, despite the east-west moisture gradient across the continent. Irrigation was unlikely to have interfered with the pattern, as no data from irrigated growing seasons were included, although in one study (Sanderson et al. 1999 b) irrigation was used in the establishment year, potentially alleviating moisture stress at a sensitive life stage. Some studies have reported longitudinal differences in yield, and longitudinal adaptations among populations (Casler \& Boe 2003). Other studies have reported broad latitudinal adaptation and few cultivar differences in response to longitude (Casler et al. 2007). Many of the trials were carried out between 95 and $100^{\circ} \mathrm{W}$, leaving those longitudes overrepresented, especially in the lowland ecotype. In upland ecotypes, maximum yields appeared to decrease west of $90^{\circ} \mathrm{W}$, whereas in the lowland cultivars, both the lowest and the highest yield values were found between 97 and $99^{\circ} \mathrm{W}$, where many of the observations were made. No stands of the lowland ecotype were planted west of $100^{\circ} \mathrm{W}$.

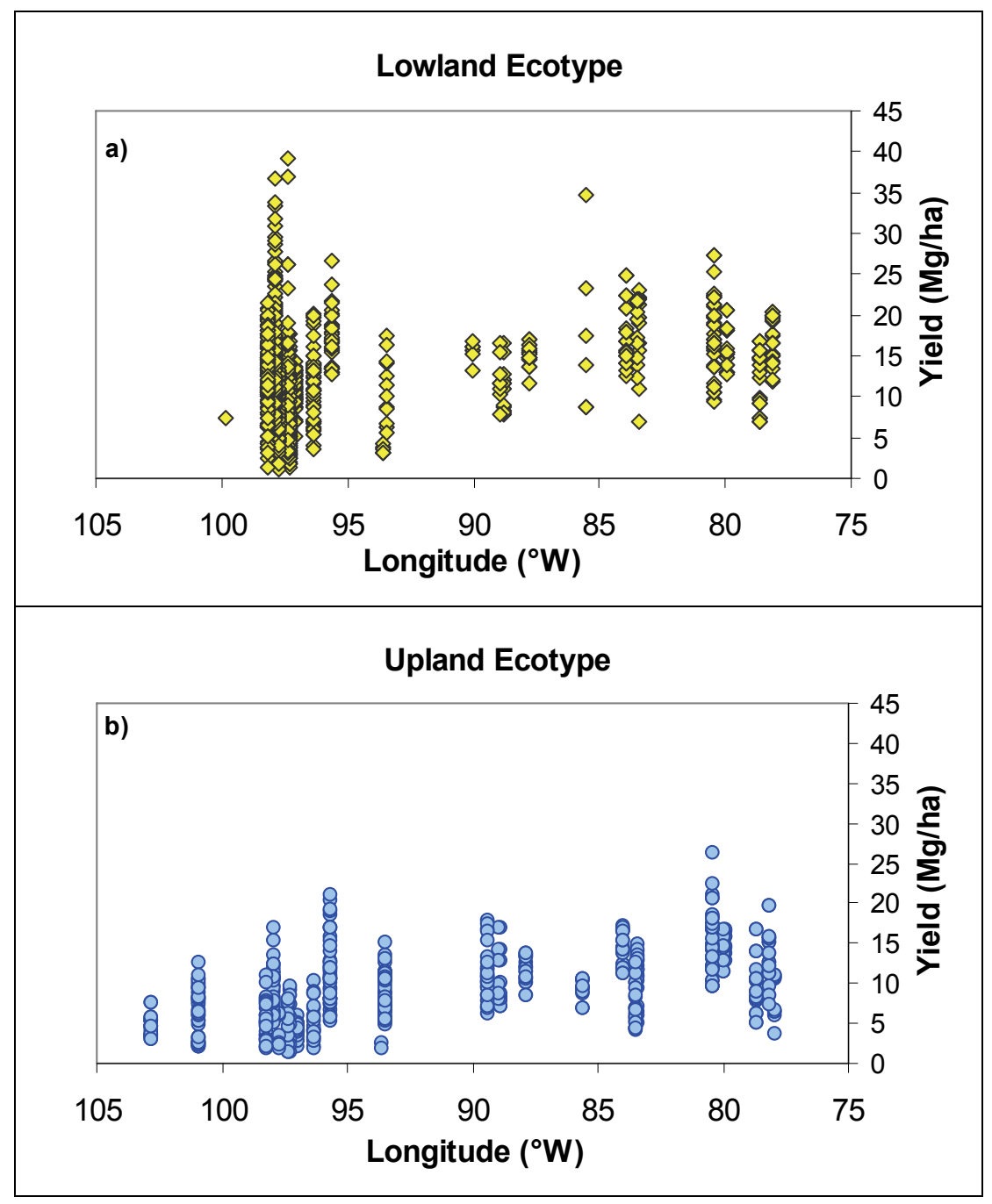

Fig. 8. Yield as a function of longitude in lowland and upland ecotypes. Yields are in $\mathrm{Mg}$ dry mass/ha. 
Latitudinal and longitudinal patterns of yield, although empirically useful, offer no mechanistic explanation of yield differences. Differences in latitude and longitude often correspond with gradients in climate and soil resources, however. Day lengths, temperatures, and growing season duration vary with latitude. Precipitation patterns, soil textures and nutrient availability also vary spatially, some along gradients associated with latitude or longitudinal. Empirical observations of yield as a function of latitude and longitude, however, might be less useful than relationships based on the climatic, edaphic, or management records associated with the experimental plots. Although average climatic patterns are well established, actual temperature and rainfall at a site may differ significantly from year to year. Similarly, crop management regimes, including planting, harvesting, and fertilization schemes can alter productivity. Further exploration of the statistical relationships within this dataset was therefore based on relationships between switchgrass yield and specific quantifiable management regimes, soil properties, nutrient application rates, and year-specific climatic variables. A better understanding of the relationships should facilitate prediction of yields outside of the current range of cultivation, where the latitudinal relationships might not be expected to be maintained.

\section{Crop Management Factors}

There were no apparent patterns of yield in relation to plot size or row spacing across these experiments. Yields ranged from less than 5 to more than $20 \mathrm{Mg} / \mathrm{ha}$ across all plot sizes. This suggests that yields were not influenced by undue management attention to small individual plots, and that second-year and subsequent harvests of switchgrass, a perennial which spreads vegetatively, are not particularly sensitive to original planting density. It has been observed that over time, tillering of surviving plants may even compensate for loss of adjacent plants (Vogel et al. 2002).

There was not a strong response of switchgrass yield to the addition of nitrogen fertilizer, either for all cultivars or by ecotype (Figures 9- 10), and variability was high. This analysis did not take into account the timing of $\mathrm{N}$ application, whether or not other nutrients were added, or the $\mathrm{N}$ availability in native soil. For lowland types (Figure 9a), the response appeared to plateau far below the highest two rates of $\mathrm{N}$ application. In the detailed plot of low application rates only, (Figure 9b) there was a hint of an optimum around $90 \mathrm{~kg} \mathrm{~N} / \mathrm{ha}$, but in many cases the zero fertilizer plantings did as well as any fertilized stands. In upland ecotypes (Figure 10), yields appeared to respond to total rates of $\mathrm{N}$ application up to approximately $100 \mathrm{~kg} / \mathrm{ha}$, and appeared to decrease above those rates, although there were fewer observations at higher application rates, and none above $160 \mathrm{~kg} / \mathrm{ha}$, which could be compared to the lowland responses of Figure 9. Very high levels of fertilization certainly did not guarantee increased biomass production. Although there were no very low yields at $\mathrm{N}$ application rates greater than $200 \mathrm{~kg} \mathrm{ha}^{-1}$, these rates were applied only to lowland cultivars, which had generally higher yields in all cases, and some low yields were observed between 120 and $140 \mathrm{~kg} / \mathrm{ha}$ in both ecotypes.

Insensitivity to heavy fertilization was reported in some individual studies focused specifically on fertilization, e.g., Thomason et al. (2004), who did not see a strong response to variation in either rate or timing of $\mathrm{N}$ application, whereas Muir et al. (2001) saw yields increase with $\mathrm{N}$ application 
from zero to 170 or $224 \mathrm{~kg} / \mathrm{ha}$. Parrish and Fike (2005) summarize the issue of $\mathrm{N}$ application in switchgrass as "unsettled", and suggest that the range of recommendations for $\mathrm{N}$ management "is not narrowing, nor is a central tendency developing". They describe switchgrass as a plant that is inherently N-thrifty, especially when managed for biomass. Although the biomass yield summaries here did not appear to show a strong response to fertilization, particularly not to high levels of $\mathrm{N}$ application, response to $\mathrm{N}$ at low application rates may still be relevant in modeling.
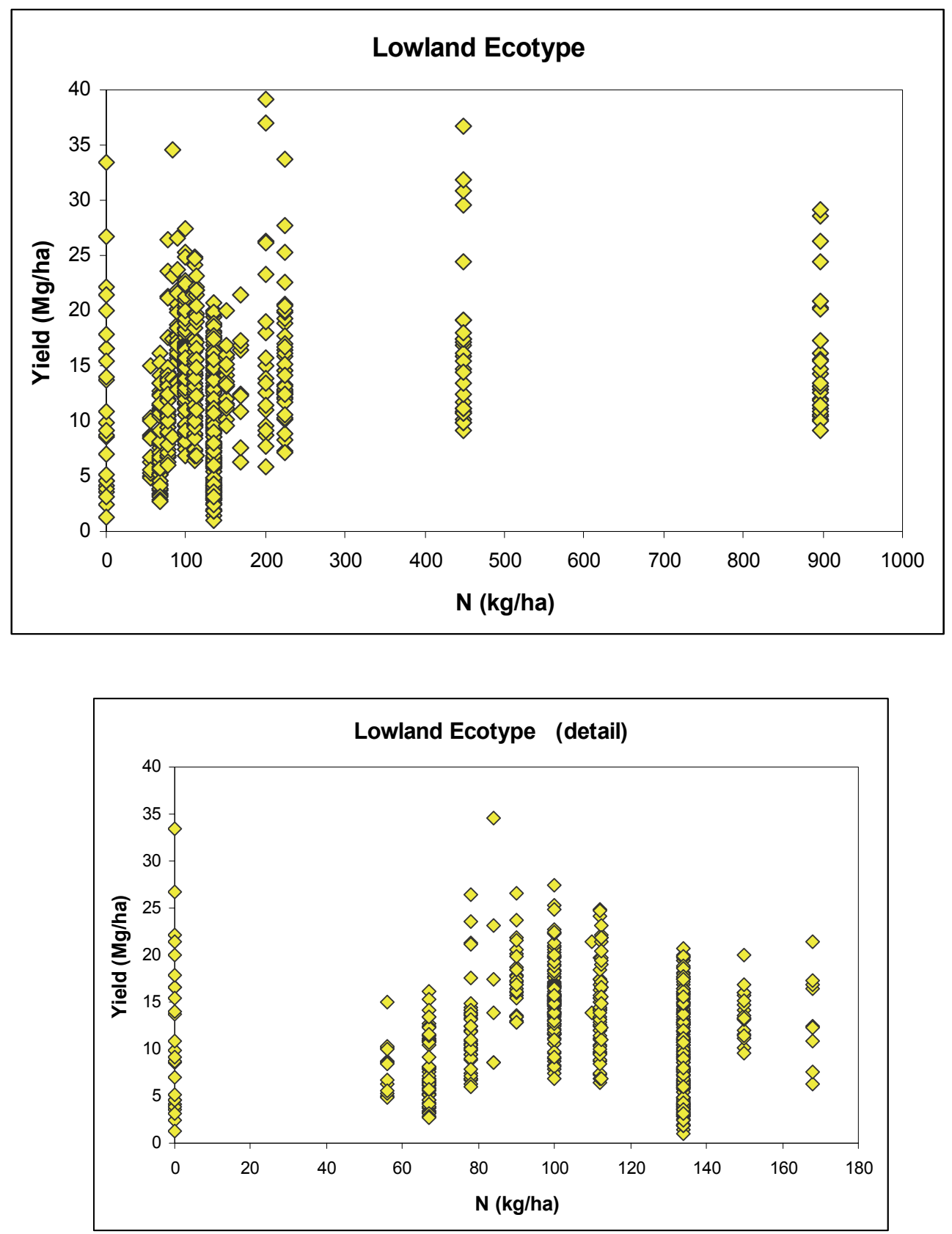

Fig. 9. Yield in lowland ecotypes as a function of total nitrogen applied during the growing season. Shown over the entire range (upper panel) and over a range of lower applications rates (lower panel), similar to those rates applied to upland ecotypes. 


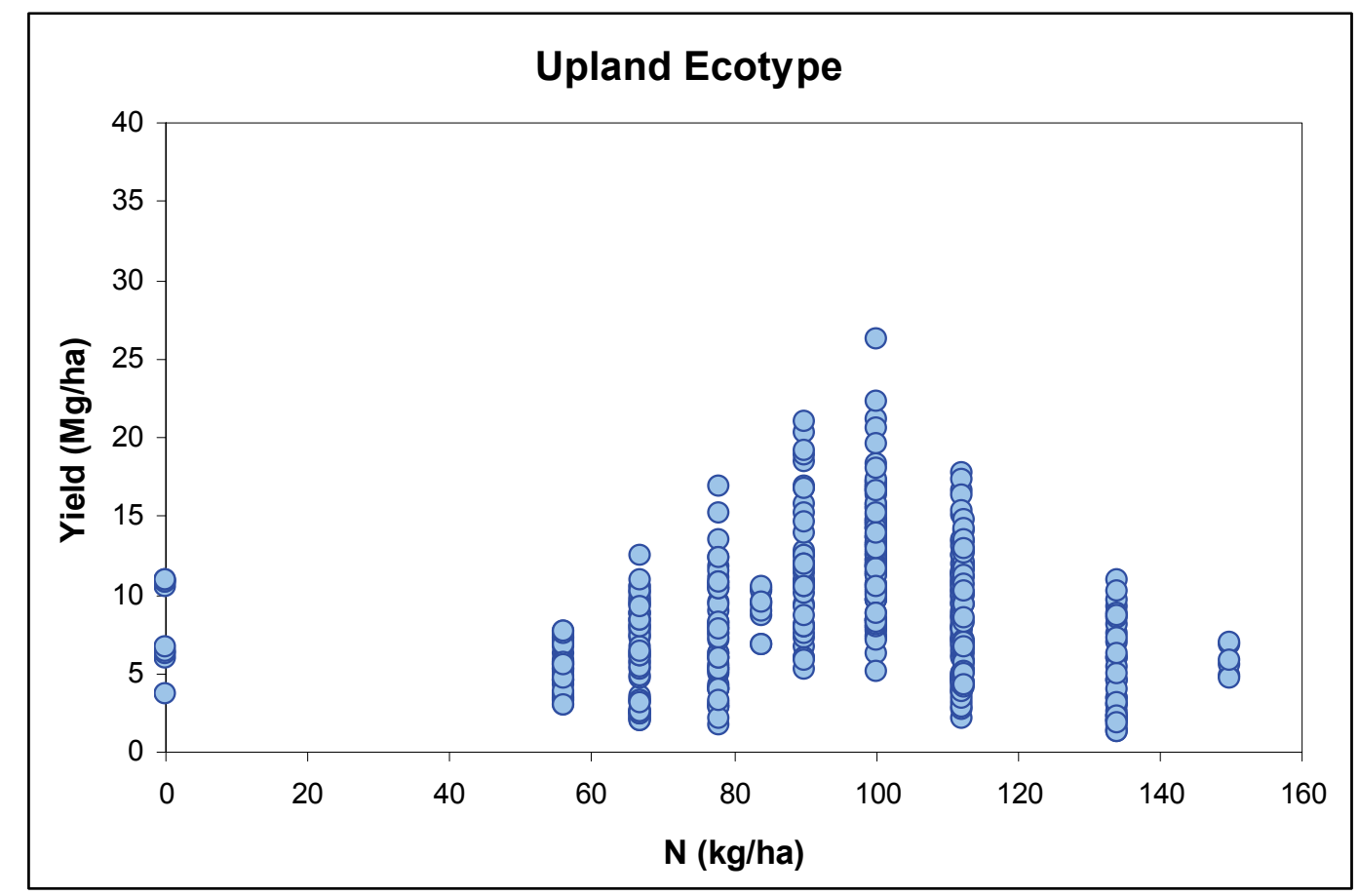

Fig. 10. Yield in upland ecotypes as a function of total nitrogen application during the growing season.

\section{Soil and Climate}

Switchgrass is native in regions representing a wide variety of soil types, and it may be adapted to perform well in a variety of soil textures, in soils low in nutrients, and in otherwise marginal growing conditions. Both soil type per se and soil acidity have been discounted as major determinants of switchgrass productivity (Parrish \& Fike 2005), yet spatial variation in soil parameters may impact switchgrass yields even within a single field (Di Virgilio et al. 2007). In this analysis, there was not an obvious response of yield to variation in soil texture, i.e., no clear pattern as a function of sand, silt, or clay content as a percentage (data not shown), at least at the available resolution of soil texture data. Given the many other factors contributing to variability, none of the soil texture variables alone explained yield differences. An interaction between precipitation and soil texture might nevertheless impact yield, as relative amounts of sand, silt and clay control soil water-holding capacity, with implications for seedling survival and yield even at the same level of precipitation (Evers \& Parsons 2003, Parrish \& Fike 2005). Likewise soil texture could influence rooting depth and nutrient availability, but these relationships were not within the scope of the analysis.

The final variables addressed were the climatic variables of precipitation and temperature, at both an annual and growing season level, for the specific year and location corresponding to a yield value. Not all studies provided data on annual or growing season precipitation and temperatures, and in order to include as much of the yield data as possible, we made use of nearest weather 
station data as described earlier. For consistency, these weather station values were used for all observations.

\section{Precipitation}

Switchgrass biomass yield as a function of growing season precipitation (growing season defined as April through September for the purposes of this analysis) was highly variable (Figure 11), indicating that precipitation alone could not explain yield differences. Unlike the pattern seen for yield in relation to latitude (Figures 5-7), low yield values were observed across all values of precipitation, with no strong correlation between yield and rainfall in either ecotype (Figures 12 and 13). If the upper boundaries of the relationship represent the maximum potential yield, however, low rainfall during the growing season did appear to limit yield. Particularly in the upland ecotype (Figure 13), yield increased with an increase in April-September rainfall, up to a threshold of approximately $600 \mathrm{~mm}$ rainfall. Above $600 \mathrm{~mm}$, rainfall did not appear to limit growth in either ecotype.

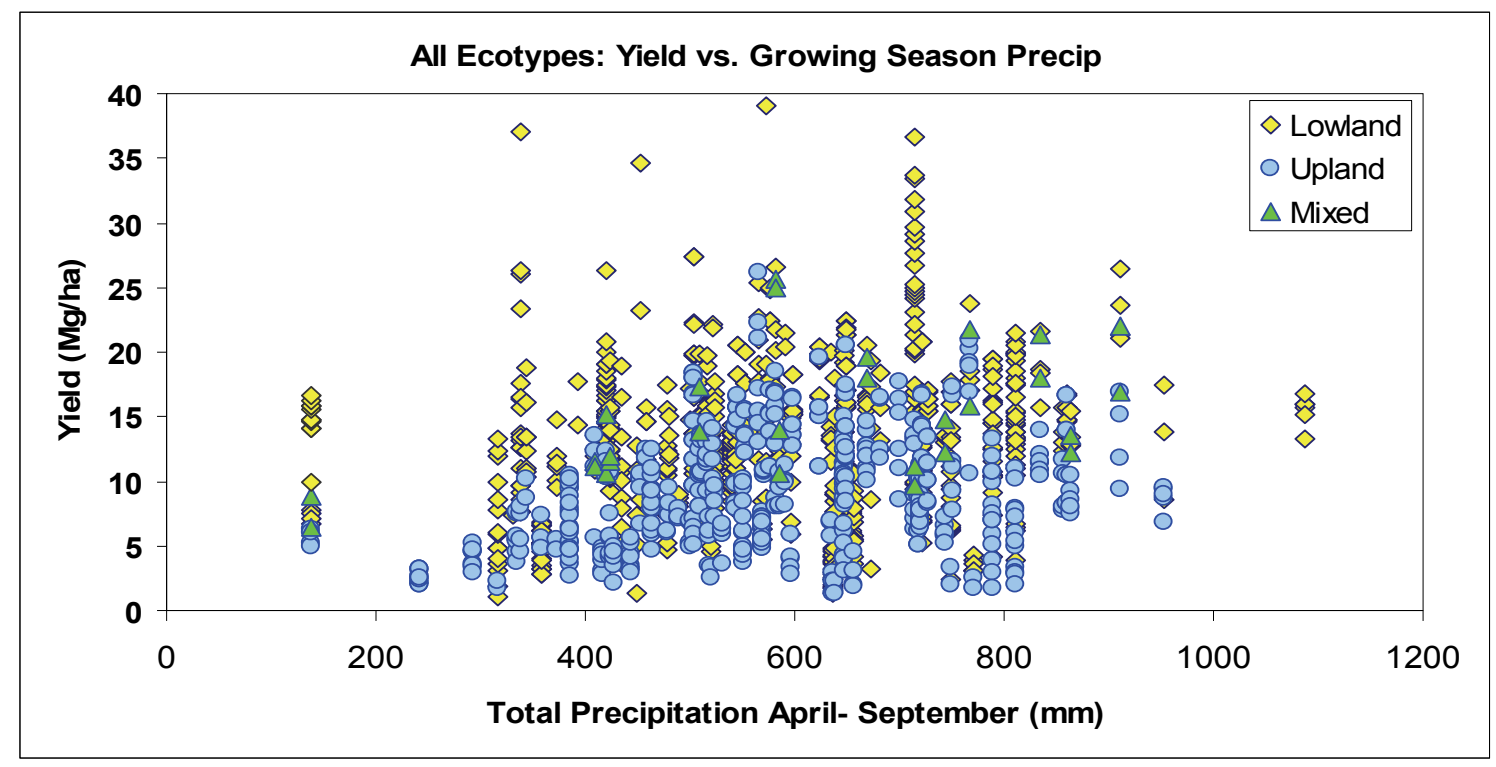

Fig. 11. Yield as a function of growing season precipitation in all studies.

Total precipitation is only one factor contributing to soil moisture availability. The timing and size of rainfall events is an important modifier; in particular, sufficient rainfall must occur during more critical portions of the growing season. Sanderson et al. (1999b) reported that high yields at five east Texas locations were associated with years when April-September rainfall was high, and Berdahl et al. (2005) found that low April-September rainfalls severely limited yield for 8 upland strains in North Dakota. Narrowing down the sensitive time frame in their study, Muir et al. (2001) correlated March-August precipitation with yield at Stephenville, TX. Over a four-year period in South Dakota, biomass production was best explained by a linear relationship with April-May precipitation (Lee \& Boe 2005). Because cultivars differ in phenology (Berdahl et al. 2005, Casler 2005, Parrish and Fike 2005), and locations differ in day length and growing season, it is not surprising that the period of sensitivity might vary among studies. Management factors 
play a role as well; low rainfall in August-September reduced yields in a two-cut, but not in a one-cut system (Reynolds et al. 2000).

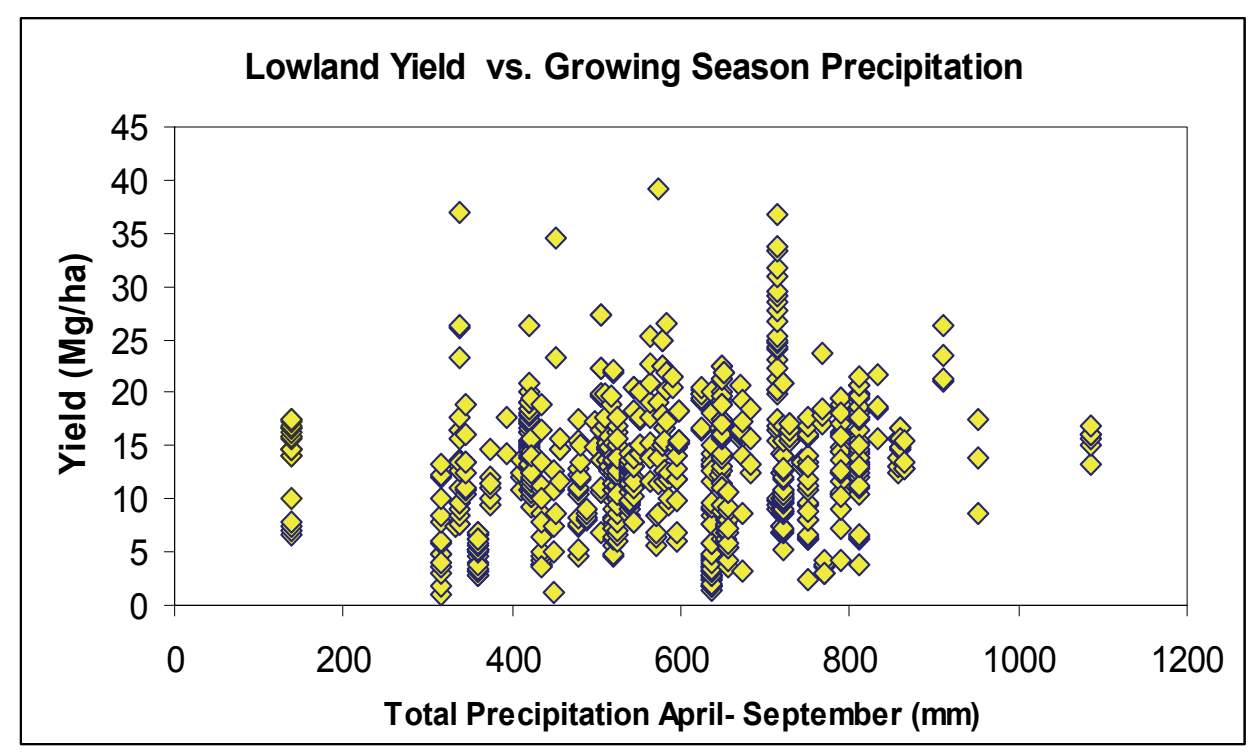

Fig. 12. Yield in lowland ecotype as a function of total precipitation, AprilSeptember.

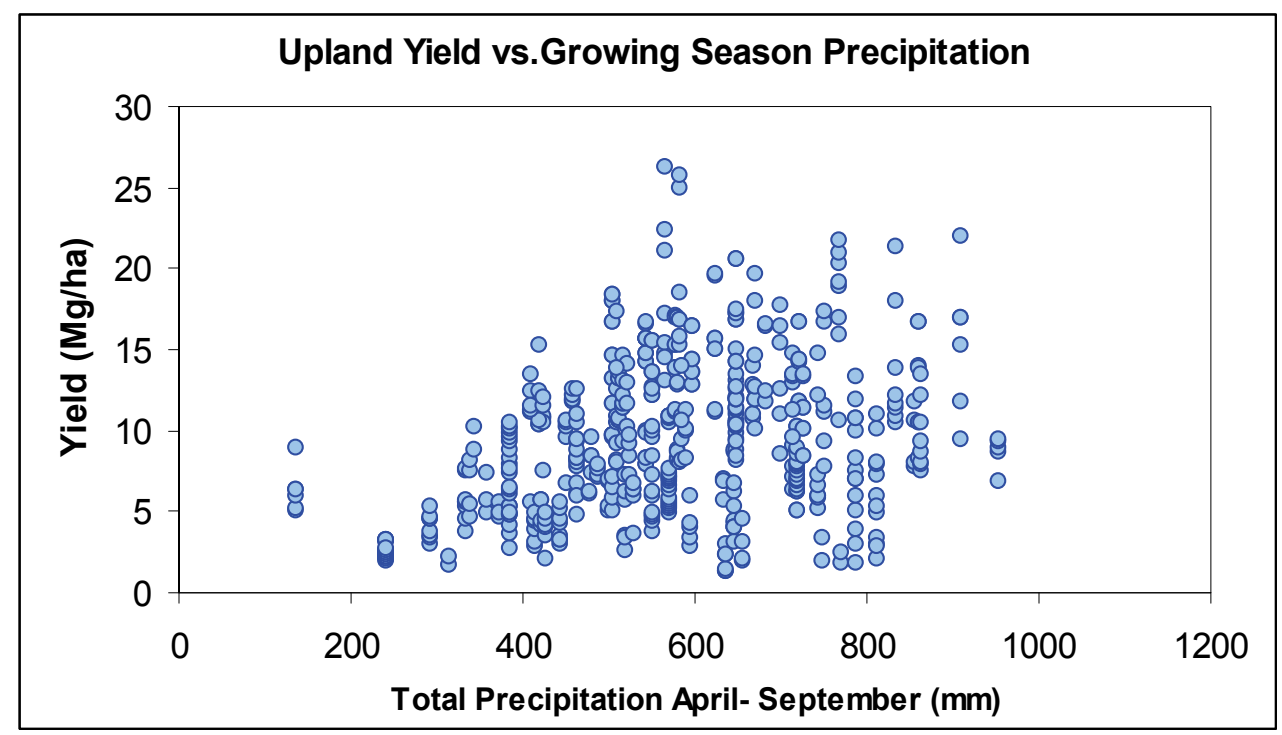

Fig. 13. Yield in upland ecotype as a function of total precipitation, AprilSeptember.

Soil texture and depth, topography (e.g., distance from a stream), supplemental irrigation, different cultivar requirements, or excess rainfall close to harvest could all confound an overall relationship between yield and annual or "growing season" precipitation (Cassida et al. 2005b). Very high growing season precipitation could also correlate with extensive cloud cover and associated low levels of solar radiation, tending to reduce yield. This type of information is not 
typically available from the literature, and in many cases does not lend itself to quantitative analysis or yield predictions, yet it can be expected to contribute to increased variability. One variable that can be eliminated in this analysis, however, is irrigation. In some of the field trials located in Texas (Sanderson et al. 1999b, Cassida et al. 2005b), plots were irrigated during the establishment years because of severe drought. Other than that, supplemental water was not provided in the studies cited. Because first year harvest data have already been excluded from this particular analysis, however, irrigation is not a factor.

\section{Temperature}

Biomass yield varied as a function of temperature, for all ecotypes taken together (Figure 14) as well as for individual ecotypes (Figures 15 and 16). In general, yields increased with increasing temperature up to a point, and then decreased. Variation was of a similar magnitude as that observed in the precipitation relationships, but the pattern was evident for minimum yields as well as maximum. The same shape curve was observed whether yield was taken as a function of growing season temperature (e.g., April- September, as shown), annual temperature, maximum summer temperature, or minimum temperature during the preceding winter. All of the temperature variables were highly inter-correlated, except that maximum summer temperature was only weakly correlated with winter minimum temperature.

Because the range of temperatures available was dependent on the growing conditions for each site during the year(s) of harvest, there were gaps in the temperature range where no yield data were available. Figures 14, 15, and 16 show this for mean growing season temperatures, but it was equally true across the ranges of the other temperature variables. These gaps hindered a full understanding of the temperature dependency of yield, as did the fact that none of the lowland ecotype cultivars were grown at sites with mean growing season temperatures below $16^{\circ} \mathrm{C}$. As a result of these gaps, as well as the relatively high variability, no difference in optimum temperatures for the two ecotypes could be determined by visual inspection.

Using any of the temperature variables, the response patterns suggest a broad optimal temperature range for yield, below and above which temperatures are detrimental. Because the climate data were correlated, it can not be determined whether conditions during all or part of the growing season, or even winter conditions, are key to understanding the temperature response of yields. Muir et al. (2001) suggested a southern limit of adaptation for Alamo between their sites in Stephenville $\left(32.22^{\circ} \mathrm{N}\right)$ and Beeville $\left(28.4^{\circ} \mathrm{N}\right)$ Texas that was unrelated to rainfall or soil type; both were described as shallow. Although temperature cannot be singled out as the limiting factor, nearest-weather-station data did indicate that mean April-September temperatures were 2 to $3{ }^{\circ} \mathrm{C}$ higher at the more southern site, averaging $26^{\circ} \mathrm{C}$ during the study. Such high temperatures could be limiting in themselves if they exceed a physiological optimum, or they might interact by increasing evapotranspiration and reducing soil moisture.

Growing season temperatures seem like an obvious correlate for yield, growth rate being expected to be temperature-dependent to some degree (Parrish \& Fike 2005). Spring 
temperatures, however, might be key; in some environments, e.g., North Dakota (Berdahl et al. 2005) and eastern Canada (Madakadze et al. 1998b), cool temperatures and short growing seasons limit switchgrass growth potential. A focus on spring temperatures would thus isolate temperature requirements for germination, bud-break, and initiation of new growth. In southwestern Quebec, for example, initial spring growth was hastened by up to 35 days by a warmer spring (Madakadze et al. 1998a). Leaf area duration also correlated with yield, and this varied across cultivars (Madakadze et al. 1998a), highlighting the interaction between genetics and environment. Similarly, in an Ohio study, cool, wet soils in spring limited planting and establishment success, and therefore yield (Turhollow 1991, Parrish \& Fike 2005), although a closer analysis suggested that subsequent drought conditions may have been at least as limiting as the cool spring (Wright 2007).

Conversely, minimum winter temperatures play a role in determining winter survival. Vogel et al. (2002) also found genetic variation in winter survival and subsequent sward recovery even within selections from a single field population. The duration of low winter temperatures would also impact the length of the growing season, and may impact survival (Vogel et al. 2002). The northern distribution limit of the species $\left(51^{\circ} \mathrm{N}\right.$ on the plains of North America, Jefferson et al. 2002) is assumed to be at least partially a function of cold winter temperatures (Vogel et al. 2002, Berdahl et al. 2005, Casler 2005, Parrish \& Fike, 2005).

Thus, although growing season temperature is a logical variable to correlate with yield, using mean annual temperatures to model yield response incorporates winter temperature differences along with differences in spring and summer temperatures, and the duration of the likely period for active growth. It is therefore a highly integrative variable, although it does not allow a mechanistic understanding of the physiological limitations.

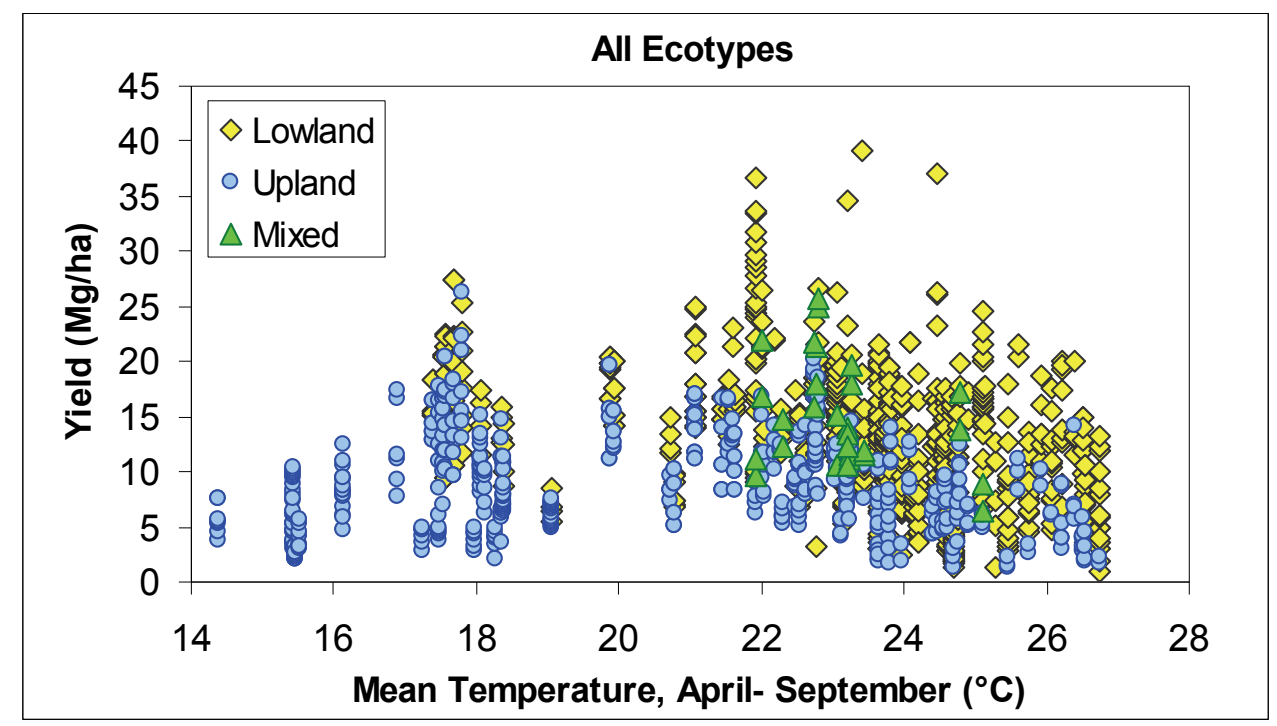

Fig. 14. Switchgrass biomass yield as a function of growing season temperature, including upland, lowland, and mixed stands. 


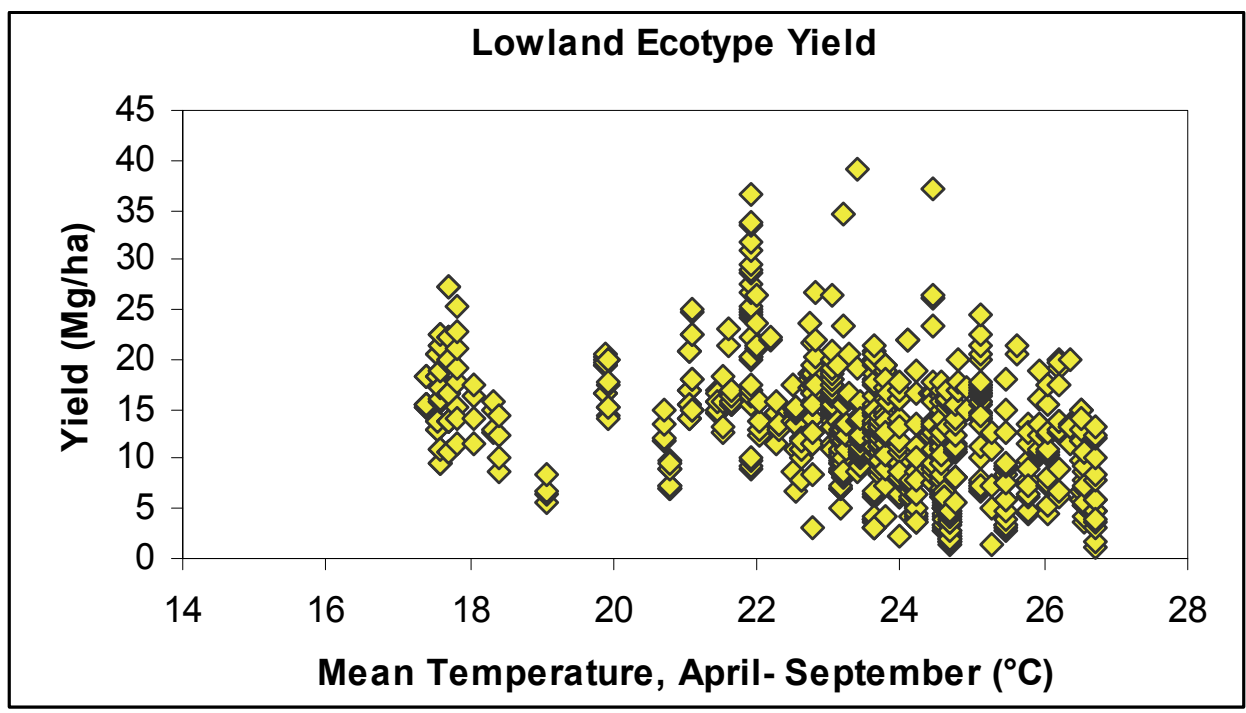

Fig. 15. Annual biomass yield in lowland ecotypes as a function of growing season temperature.

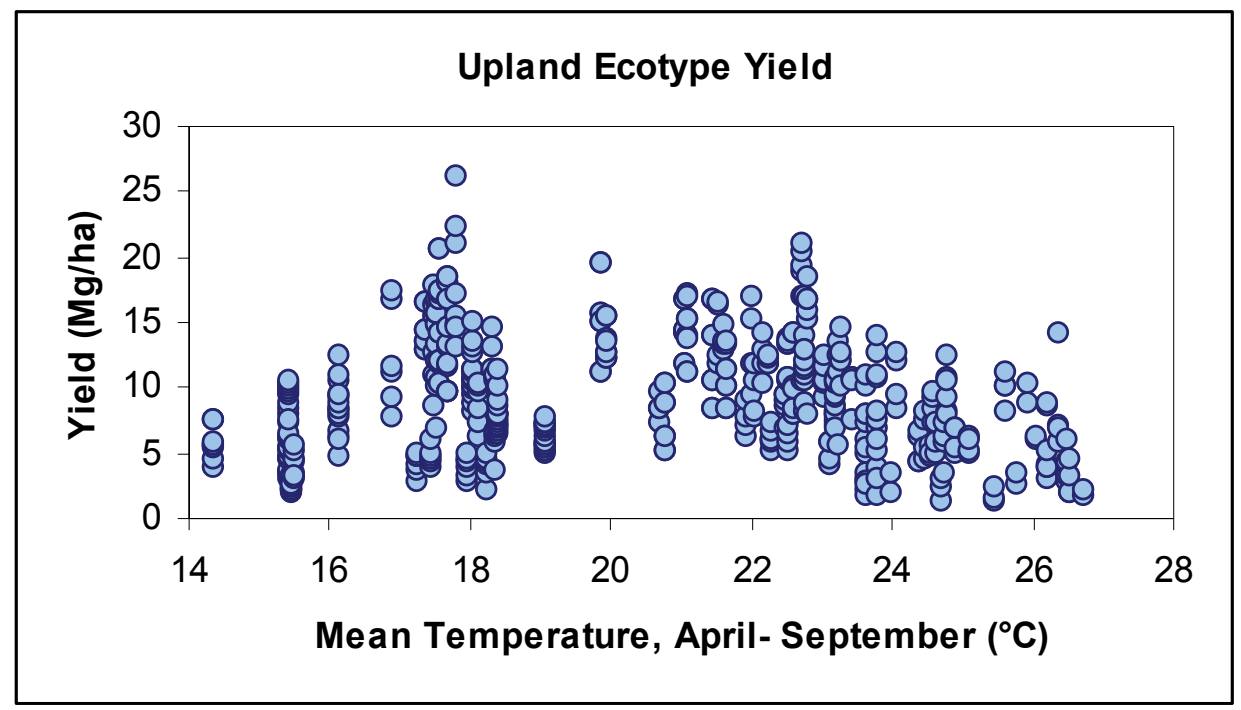

Fig. 16. Annual biomass yield in upland ecotypes as a function of growing season temperature. 


\section{MULTIVARIATE ANALYSIS}

The univariate analyses described in the previous section suggested important relationships with climate and soil, but none were sufficient to reasonably predict yields. It is well known that yield is controlled by multiple factors, making it difficult to isolate their separate influences. In this section we developed empirical models to explain switchgrass yield, using some of the climate predictors discussed earlier. For this analysis, an empirical modeling approach was chosen, based on statistical relationships between the resource variables and yield rather than on underlying biochemical and physiological mechanism. Empirical modeling is often used to estimate crop yield or productivity because of the simplicity and the smaller number of input variables required. A number of empirical approaches exist, including multiple polynomial regression, the Miami model (Lieth 1975), and limiting factor quantile regression (Cade et al. 1999, Lancaster \& Belyea 2006). The method chosen here for projecting switchgrass yields, the multiplicative optimum model, was created specifically for this project. It incorporates some of the features of the Miami model and of quantile regression, and other features conceptually rooted in models such as Linkages and portions of the Century model (Pastor \& Post 1985, Parton et al. 1993).

Because of the cytotypic and phenotypic differences between upland and lowland ecotypes of switchgrass, as well as significant differences in average yield, all modeling was done separately for the two types. Mixed stands were not included in the models. After separating the two groups, we stratified by field location and drew a test subset of two yield estimates from each location (one if two were not available). The test sets consisted of 69 and 46 observations for lowland and upland ecotypes, respectively. The remaining data were used for analysis and model development; the analysis subsets consisted of 729 and 534 observations for lowland and upland groups, respectively.

Multiple regression techniques can be used to test the statistical impacts of individual factors (and their interactions) on yield. The technique is based on least-squares fits for all factors and interactions, and can be used to determine the factors which explain the most of the variation in yield. Preliminary tests with this approach indicated that temperature and precipitation had more influence than did $\mathrm{N}$ application, stand age, or any interactions among the five variables. The Miami model, which was originally developed (Lieth 1975) to estimate global net primary productivity (NPP), is based on simple non-linear (asymptotic) functions of mean annual temperature and annual precipitation. It assumes that, for any one location and time, one of these two environmental factors constrains productivity, and it uses the minimum of two NPP estimates, one based on temperature, and one based on precipitation (Jager et al. 2000).

Most ordinary regressions, including multiple regression and the non-linear Miami model regressions, are based on least-squares fits through the data, minimizing the sum of the squares of the distance between the predicted values and the observed. These regressions represent the center of the data distribution with respect to a factor, with the variance equally distributed (Lancaster \& Belyea 2006). Unlike data from tightly controlled experiments, however, data from ecological surveys and field observations tend to be highly variable, and may be better characterized by the upper and lower limits of the distribution than by the central response 
(Lancaster \& Belyea 2006). Some researchers even suggest that conventional correlation and regression analyses are fundamentally at odds with the ecological concept of limiting factors (i.e., Leibig's Law of the Minimum), because they represent that central tendency, rather than the limit (Cade et al. 1999, Lancaster \& Belyea 2006). A well established approach that is relatively new to ecological applications (Cade et al. 1999), called quantile regression, can be used either to represent the central response to a factor or the limiting relationship. The median, or 0.50 quantile, describes the central response, analogous to ordinary least squares regression, whereas an upper quantile, e.g., the $90^{\text {th }}$ or $95^{\text {th }}$, represents the upper limit of the response function (Cade et al. 1999, Lancaster \& Belyea 2006). The underlying assumption of the upper quantile approach is that unmeasured factors constrain much of an observed response, interacting with the measured factors to create a pattern of unequal variation (Cade et al. 1999). As such, changes observed near the upper bounds of the relationship, as opposed to the center of the distribution, more accurately estimate the limiting effect of an environmental factor (Cade et al. 1999). The interior of the distribution cloud is thus filled with observations constrained by another factor.

The multiplicative optimum model (M.O.M.) combined some of the properties of the previous approaches. Using the concept of quantile regression, it used the 95th percentile response to estimate potential yield as a function of a single limiting factor, assuming that values below the $95^{\text {th }}$ percentile were limited by non-optimal levels of other factors, whether measured or unmeasured. Like the Miami model, it incorporated two non-linear functions for the responses to mean annual temperature and precipitation. Unlike the Miami model, however, it used a Gaussian curve to describe the temperature function, rather than an asymptotic function, in keeping with the observed relationships in the data (Figures 14, 15, and 16). This function implicitly assumed that high temperatures could also constrain yield in switchgrass, either by reducing a needed winter chilling period, or by exceeding an innate high temperature limit in summer.

In order to simplify estimation of the median and $95^{\text {th }}$ percentiles, the data were binned into discrete groups by temperature for the first regression, and by precipitation for the second. After the quantiles of yield for each bin were determined, a least-squares regression was fit to describe the non-linear relationship between the factor (temperature or precipitation) and the $95^{\text {th }}$ percentile of yield in the bin.

Similar to the multiple limitations used to reduce relative growth or decomposition as a function of non-optimal temperature, moisture, etc. in individual-based gap models such as Linkages (Pastor \& Post 1985) and Century (Parton et al. 1993), the regressions that were established through the $95^{\text {th }}$ percentile were then used to quantify the limitation of non-optimal temperature or precipitation as a corrective coefficient $(\leq 1)$. The two limitation coefficients were then multiplied, and multiplied by the theoretical maximum yield. This approach implicitly assumes that temperature and precipitation co-limit productivity, and may act independently and simultaneously, in keeping with the Multiple Limitation hypothesis (Rubio et al. 2003). 

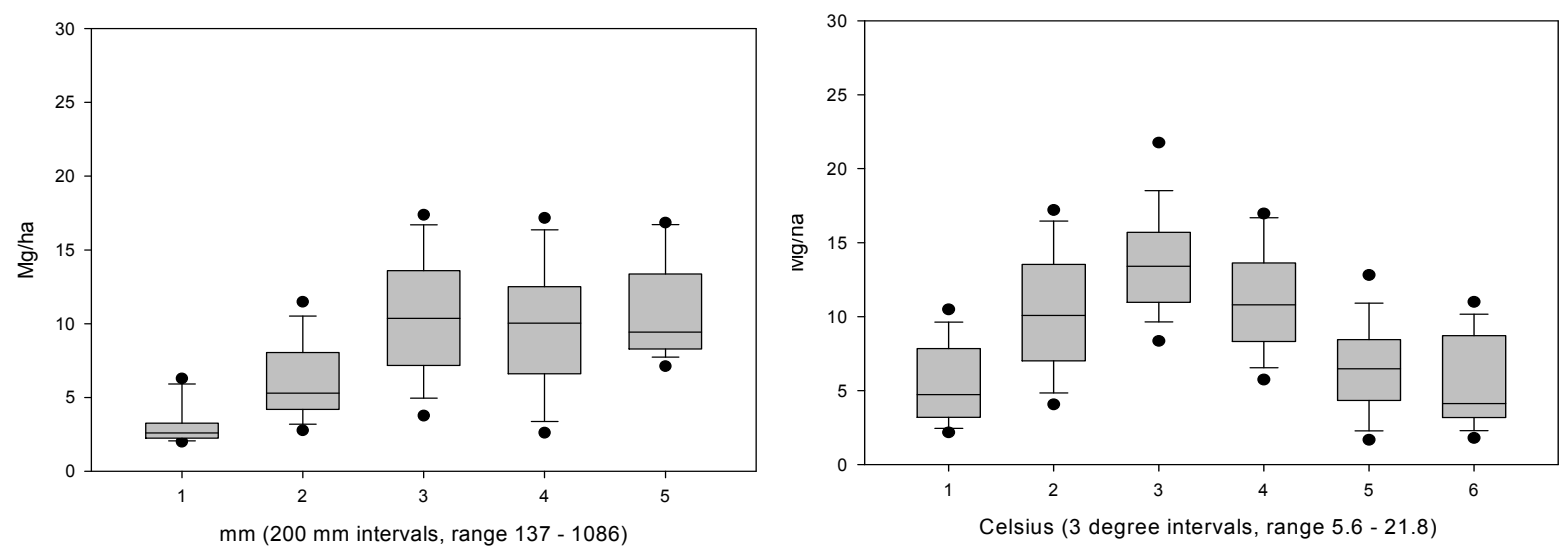

Fig. 17. Yield in upland ecotypes as a function of (left panel) precipitation, binned in 200 mm intervals, and (right panel) annual temperature, binned in $3^{\circ} \mathrm{C}$ intervals. Gray boxes indicate the $25^{\text {th }}$ and $75^{\text {th }}$ percentiles of the yields associated with the interval, with the median indicated by a horizontal bar within the box. Whiskers are the $90^{\text {th }}$ and $10^{\text {th }}$ percentiles, and closed circles represent the $5^{\text {th }}$ and $95^{\text {th }}$ percentiles of yield.

In Figure 17, box plots illustrate some of the quantiles of the yield data, as binned by precipitation (Figure 17 left panel) and temperature (Figure 17 left panel). This method revealed more clearly the relationship of yield to precipitation and temperature than did scatter plots of the entire data set (cf. Figures 13 and 16). The $90^{\text {th }}$ or $95^{\text {th }}$ percentile can easily be viewed as the upper limit for potential yield at the level of precipitation or temperature represented by a bin interval. Where other factors are limiting, yield would be reduced below the potential. A subsequent least squares regression through an upper percentile should adequately represent this limiting relationship, but because of the artificially reduced scatter, the variability and goodness-of-fit estimates will not represent the relationship with the field data.

\section{Regression analysis}

The limitation of precipitation on maximum yield was modeled with a hyperbolic curve (Equation 1).

$$
\text { Yield }_{P 95}=\left\{\begin{array}{r}
a, P \geq P_{u} \\
(1+c P)^{\frac{1}{d}}
\end{array}\right), \quad \begin{array}{r}
P_{c} \leq P<P_{u} \\
0, \quad P<P_{c}
\end{array}
$$


The dependent variable in Equation 1 is the $95^{\text {th }}$ percentile of yield for field measurements falling in the precipitation interval, variable $\mathrm{P}$ is the average total growing season precipitation for observations in each precipitation interval, and a, b, c, and d are estimated parameters.

The temperature limitation was similarly modeled using a Gaussian curve of the form:

$$
\text { Yield }_{T 95}=r \mathrm{e}^{\left(-0.5 \cdot\left(\frac{\left(T-x_{0}\right)}{s}\right)^{2}\right)}
$$

where Yield ${ }_{\mathrm{T} 95}$ is the $95^{\text {th }}$ percentile of yield measurements in the temperature interval, and $\mathrm{T}$ is the average of mean annual temperatures for observations in the temperature interval. Parameters $\mathrm{x}_{0}$ and $\mathrm{s}$ can be interpreted as the mean and variance of a Gaussian distribution of temperatures.

Upland Yield x Growing Season Precipitation

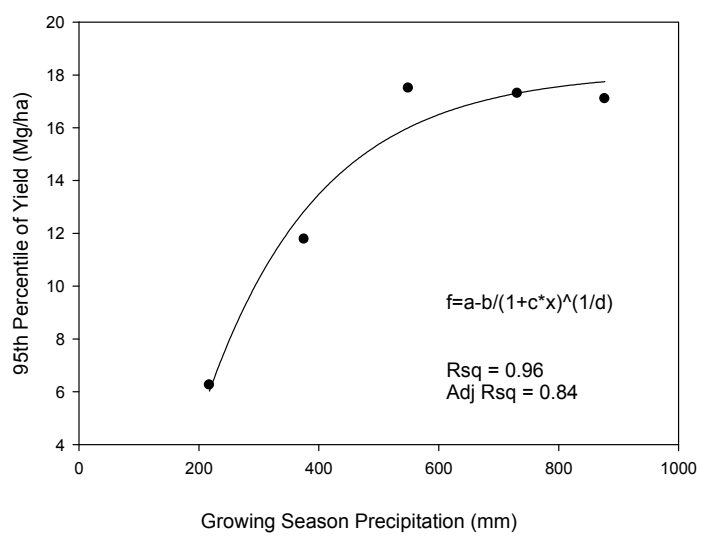

Upland Yield x Annual Temperature

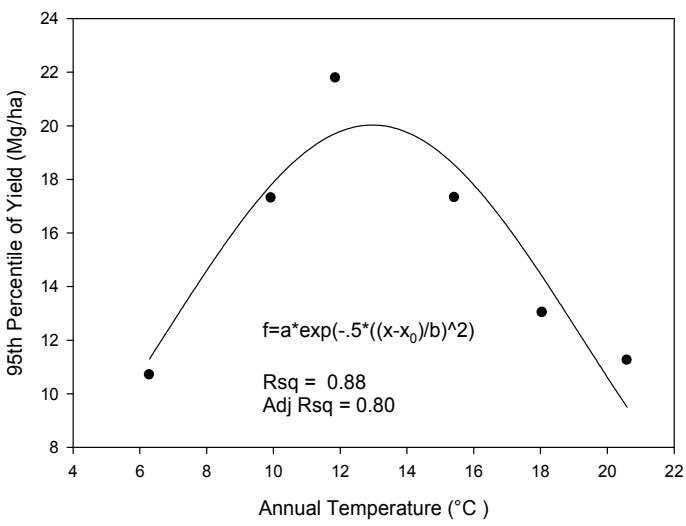

Fig. 18. Regressions through the $95^{\text {th }}$ percentile of upland ecotype yield as a function of (left panel) growing season precipitation and (right panel) mean annual temperature in intervals as described in the text. In the legend of panel (b), $a$ represents $r$ and $b$ represents $s$ as defined in Eq. 2. The form of the equation and $\mathrm{R}^{2}$ values are shown on the plots.

For the binned data of upland ecotypes, the results of regressions through the $95^{\text {th }}$ percentile of yield are shown in Figure 18 for precipitation and temperature, respectively. For precipitation, the parameters for the upland ecotype were as follows: $a=18.1, b=37.9, c=7.94 \times 10^{-7}$ and $d=$ 0.0002 . For temperature, the parameters were: $\mathrm{r}=20.0, \mathrm{~s}=6.24$, and $\mathrm{x}_{0}=12.97$ for upland ecotypes.

Similarly, Figure 19 shows the relationships of potential yield to precipitation and temperature for lowland ecotypes. For the lowland ecotypes, the parameters for the precipitation relationship were the following: $\mathrm{a}=23.8, \mathrm{~b}=27.9, \mathrm{c}=-0.0011$ and $\mathrm{d}=-0.29$. For temperature, the lowland parameters were: $\mathrm{r}=26.8, \mathrm{~s}=6.15$, and $\mathrm{x}_{0}=14.75$. 
Lowland Yield x Growing Season Precipitation

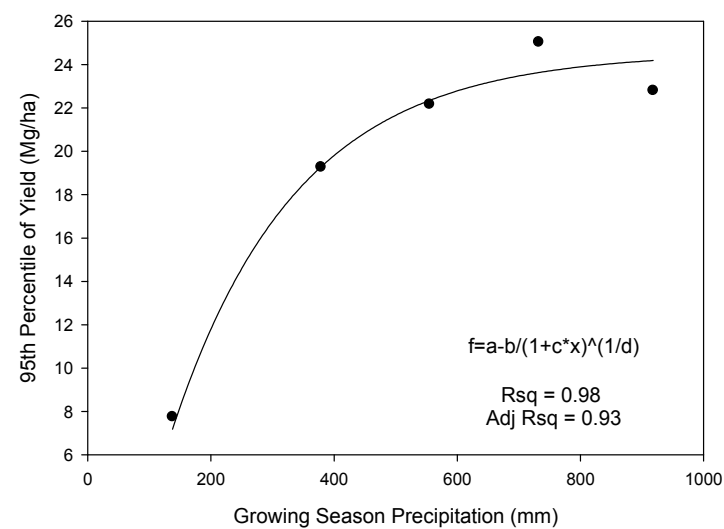

a)
Lowland Yield x Annual Temperature

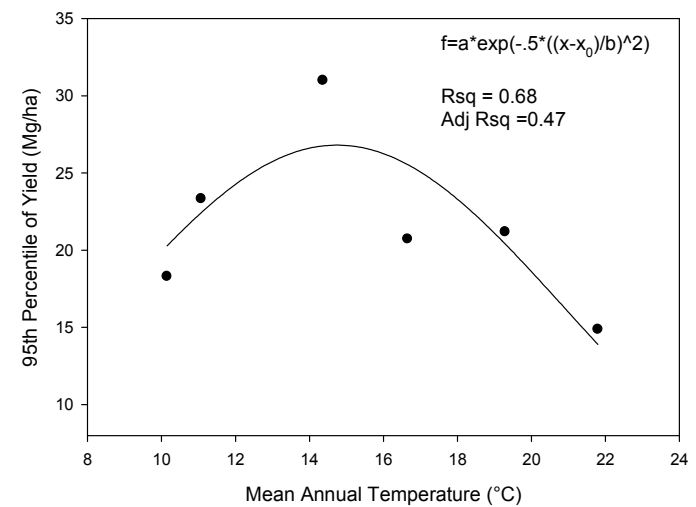

b)

Fig. 19. Regressions through the $95^{\text {th }}$ percentile of lowland ecotype yield, as a function of (a) growing season precipitation and (b) annual temperature intervals as described in the text. In the legend of panel (b), $a$ represents $r$ and $b$ represents $s$ as defined in Eq. 2. The form of the equation and $\mathrm{R}^{2}$ values are shown on the plots.

When compared to scatter plots of the entire data set (Figures 13 and 16 for upland, and Figures 12 and 15 for lowland ecotypes), the $95^{\text {th }}$ percentile plots (Figures 18 and 19) present less scatter, and the relationships of potential yield to limitation by the independent variables should be more readily quantified. This was certainly true for three of the relationships, but $\mathrm{R}^{2}$ values were lower for yield vs. temperature in lowland ecotypes, where some points deviated noticeably from the model. This could indicate a weaker relationship, but is just as likely an inescapable consequence of the data reduction inherent in this technique. With a data set of this size and structure, quantile values are susceptible to random variation associated with the particular bin sizes and boundaries used in the analysis. Discrepancies may be associated with a bin containing few observations, or with a bin containing a large number of observations from a single combination of site and growing season.

\section{Yield predictions for the test data set}

Using the regression equations shown in Figures 18 and 19, the temperature and precipitation values associated with each observation in the reserved test data set were used to independently predict the highest $\left(95^{\text {th }}\right.$ percentile) yield that could be expected at a given temperature (Yield $\left.\mathbf{T}_{\mathbf{T 9 5}}\right)$ and precipitation (Yield $\mathbf{P}_{\mathbf{P 5}}$ ). Each highest expected yield was then divided by the modeled maximum yield for that ecotype and environmental variable. These divisors were equal to the values of parameter $\boldsymbol{a}$ in Equation 1 ( $\boldsymbol{a}$ is the asymptote, $\mathbf{Y}_{\mathbf{P}_{-} \max }$ ) or in Equation $\mathbf{2}$ ( $\boldsymbol{r}$ is the

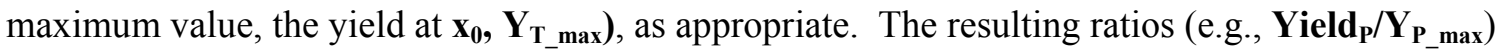
were taken to reflect the influence of the environmental condition on yield, e.g., temperature might limit yield to 0.85 of maximum, and precipitation might limit yield to 0.75 of its potential. These coefficients were then multiplied to represent the combined limitation, e.g., yield would be 
limited to $0.85 \times 0.75=0.64$ of its potential in the example given. The total limitation was then multiplied by the potential yield for the ecotype, Yield $\mathbf{m a x}_{\max }$, defined as the mean of $\mathbf{Y}_{\mathbf{P}_{-} \max }$ and $\mathbf{Y}_{\mathbf{T}_{-} \max }$ for the ecotype. In other words, the final predictive equation (defined for each of the two ecotypes) used in the multiplicative optimum model was:

$$
Y=\left(\frac{Y_{T 95}}{Y_{T \max }}\right)\left(\frac{Y_{P 95}}{Y_{P \max }}\right)
$$

\section{MODEL RESULTS}

The theoretical limitations to yield by either temperature or precipitation alone are shown for test data sets of both ecotypes in Figure 20. The theoretical temperature limits (Figure 20) agree with the general understanding that lowland ecotypes perform better in warmer environments and upland in cooler ones. As previously noted, however, conclusions on lowland ecotype yields at cold temperatures are hampered by lack of data. More surprisingly, the regressions suggest that lowland ecotypes are less subject to yield limitations under dry conditions, continuing to achieve $70 \%$ of maximum yield at $300 \mathrm{~mm}$ of rainfall as opposed to the reduction to $36 \%$ of maximal in upland cultivars. Because the actual bounds of the "growing season" per se would differ among locations, and from year to year, however, in relation to accumulated temperature sums, using a fixed April- September time period to quantify growing season precipitation could be somewhat misleading.

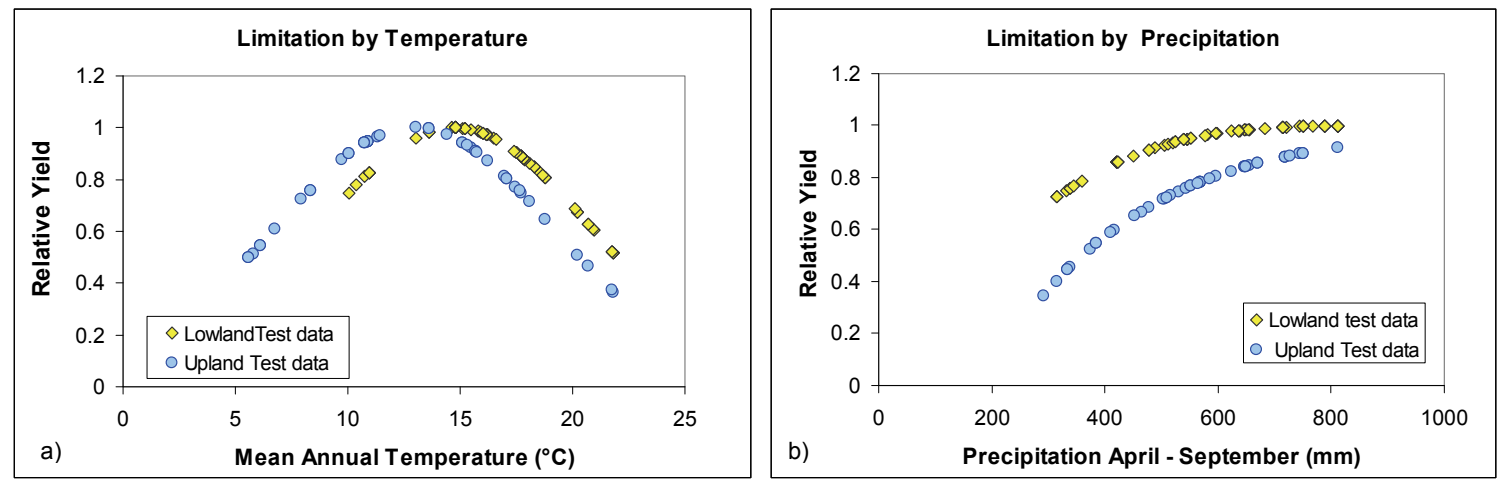

Fig. 20. Relative limitation of yield by non-optimal temperature (a) and precipitation (b) in lowland and upland ecotypes of switchgrass.

Comparing the predicted yield values (calculated using the model) to the observed yields (Figure 21) reveals that the model over-predicted yield in most cases, more so in the lowland ecotype. The $\mathrm{R}^{2}$ values were low ( 0.2 and 0.27 for lowland and upland types, respectively) and the root mean square error values were high (8.9 and 4.9). There was also an obvious bias in the predictions with respect to actual yield, as shown by the residuals (Figure 21), such that the model over-predicted most of the low yields, and under-predicted the highest yields in each 
ecotype. Additional analysis of the residuals showed no bias with respect to temperature or precipitation.
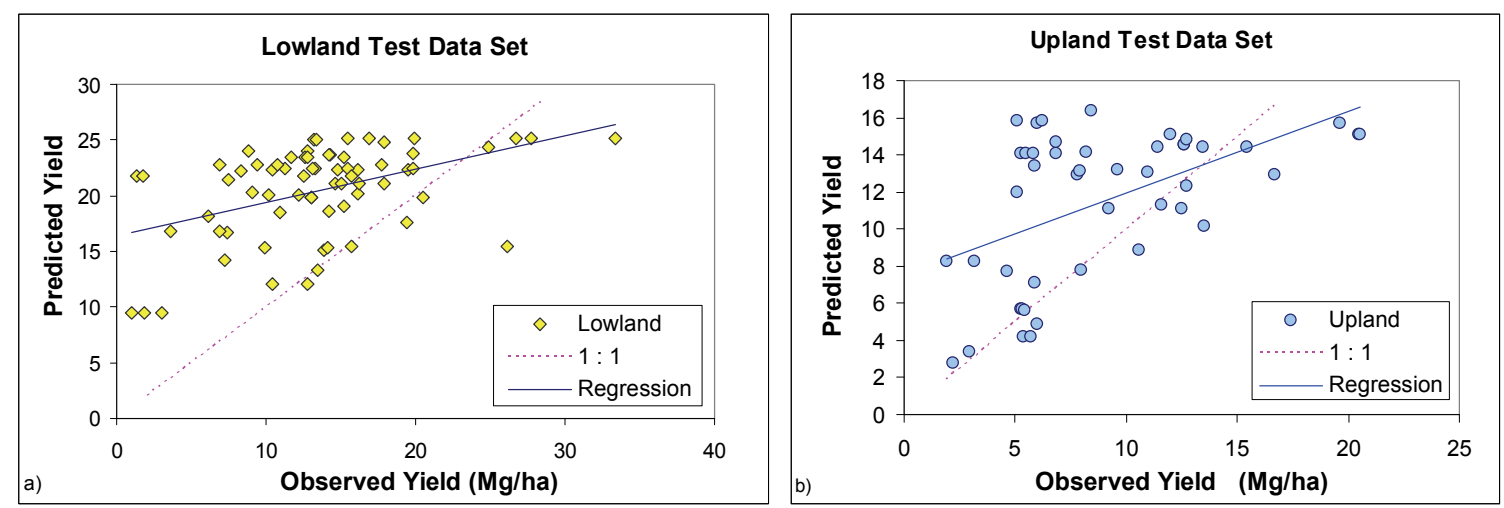

Fig. 21. Predicted optimal yields in comparison to observed yields in the reserved test data sets. Optimum yields were predicted by applying the multiplicative optimum model to the weather pattern associated with each observation for a) lowland and b) upland ecotypes. Solid lines are linear regressions through the data. The pink dashed lines are a 1:1 line (prediction $=$ observed).

What the model did predict was an upper boundary for yield. Very few field observations fell above the predicted values, that is, to the right of the 1:1 lines in Figure 21. In accordance with the model name, "multiplicative optimum", the predictions formed a theoretical upper limit for the yields that could be expected at a given combination of temperature and precipitation, if other factors were optimal.

Plotting the observed and predicted values against temperature and precipitation (Figure 21) helps clarify the patterns with respect to the two predictor variables. Only three or four of the observed yields were greater than predicted using the combined environmental constraints, but many fell short of the modeled (optimal) yields. Secondly, even though predicted yields are a function of the simultaneous constraints of temperature and precipitation, the shapes that define the primary (plotted) limitation were still evident. This was especially true in the plots as a function of temperature (Figure 21a and c), where few predictions fell very much below an upper Gaussian-shaped limit. The hyperbolic responses were also apparent in the plots of predicted yield as a function of precipitation (Figure 21b and d), although quite a few of the predictions did land in the interior of the distribution. The persistence of distinct patterns in the predicted yields suggests that, in the environments represented by the test data set, both factors would impose a small degree of limitation, and that limitation by low precipitation would contribute few additional constraints after temperature limitations were considered. In the lowland data, for example, the relative limitation by temperature was as much as $50 \%$ in some cases, whereas precipitation only limited yield by approximately $30 \%$ at most, and there was little correlation between the two limitations. In contrast, both temperature and precipitation limited upland yields by as much as $60 \%$ or more, and the limitations tended to co-occur, with the temperature limitation usually dominating. 
Regardless of the theoretical limitations to yield, a large number of the observed yields were well within the interior of the predicted distributions (Figure 22). Yields were as low as 4\% and $10 \%$ of the theoretical maximum in the lowland and upland data, respectively. As reasoned for quantile regression in general, the predicted values here represent the nature and magnitude of the known limitations to yield (the combined effects of temperature and precipitation), and the observations that fall below the prediction curves are considered to be limited by factors not accounted for in the analysis.

In the case of switchgrass yield, other sources of variation have already been noted. Cultivar differences (Figure 4) were important, and very low rates of nitrogen application (Figures 9 and 10) reduced yield at many locations. Even after eliminating $1^{\text {st }}$-year results and 4 -harvests systems, stand age and harvest frequency, especially in combination with weather, could play a role difficult to quantify, e.g., low precipitation during one of three harvest intervals. In addition, yield could be influenced by factors that were not quantified across the data set, such as soil $\mathrm{pH}$, inherent soil fertility, other nutrients, total solar radiation (vs. long periods of cloud cover), actual growing season length, day length, accumulated growing degree days, winter minimum temperatures, etc., as well as by factors that are truly unknown.

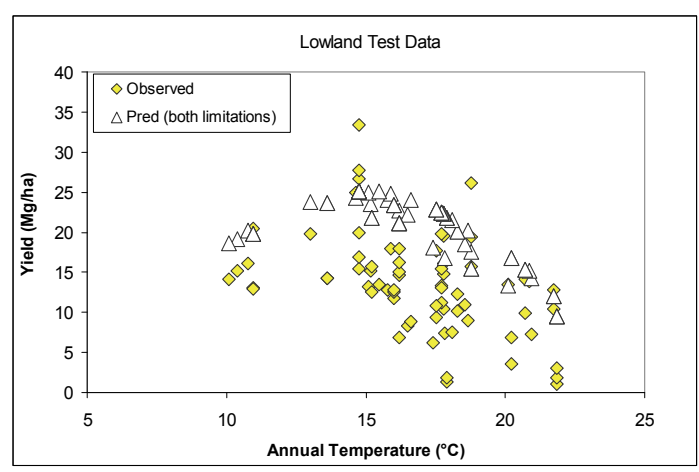

a)

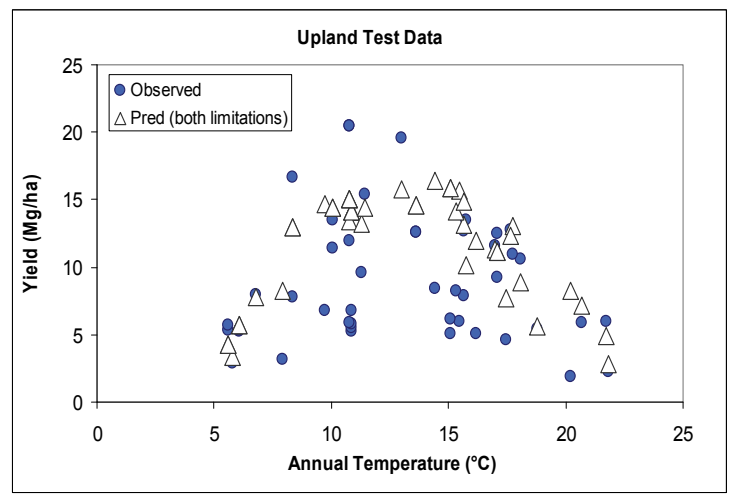

c)

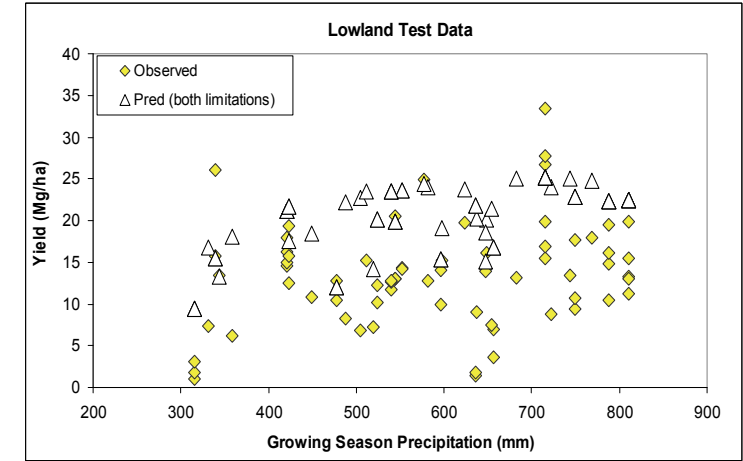

b)

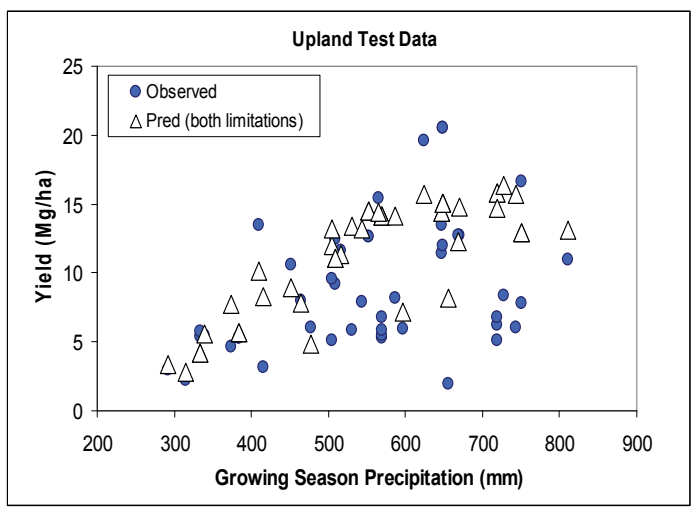

d)

Fig. 22. Yield (solid symbols) and predicted (multiplicative optimum model) yield (open triangles). Yield plotted in relation to temperature $(a, c)$ and precipitation $(b, d)$ in lowland $(a$, b) and upland (b, c) ecotypes. 


\section{SPATIAL PREDICTION OF SWITCHGRASS YIELDS}

The final objective of the project was to use the model developed here to improve estimates of switchgrass yields across the continental United States. The multiplicative optimum model provides projections of the highest potential yields expected, as a function of long-term climatic patterns, assuming the choice of high-performing cultivars and best management practices. Because the model is a scaled response to temperature and precipitation, using accurate climate data is critical to producing accurate results. For model inputs, the 30-year mean climate records of the Parameterelevation Regressions on Independent Slopes Model (PRISM) was selected over the Daymet and New climate data sets. This is because PRISM has a significantly finer resolution, $400 \mathrm{~m}$ vs. $1 \mathrm{~km}^{2}$ and $\sim 15 \mathrm{~km}^{2}$, and better accounts for critical spatial-climate forcing factors than do the other two models. Maps 4 and 5 display the PRISM output geographically, using the long-term (1971-2000) averages of mean annual temperature and growing season precipitation, overlaid with field trial locations. The distribution of field sites demonstrates that relatively large gradients of temperature and precipitation were encompassed by the dataset, although there were relatively few data at very cool and very dry locations, e.g., the

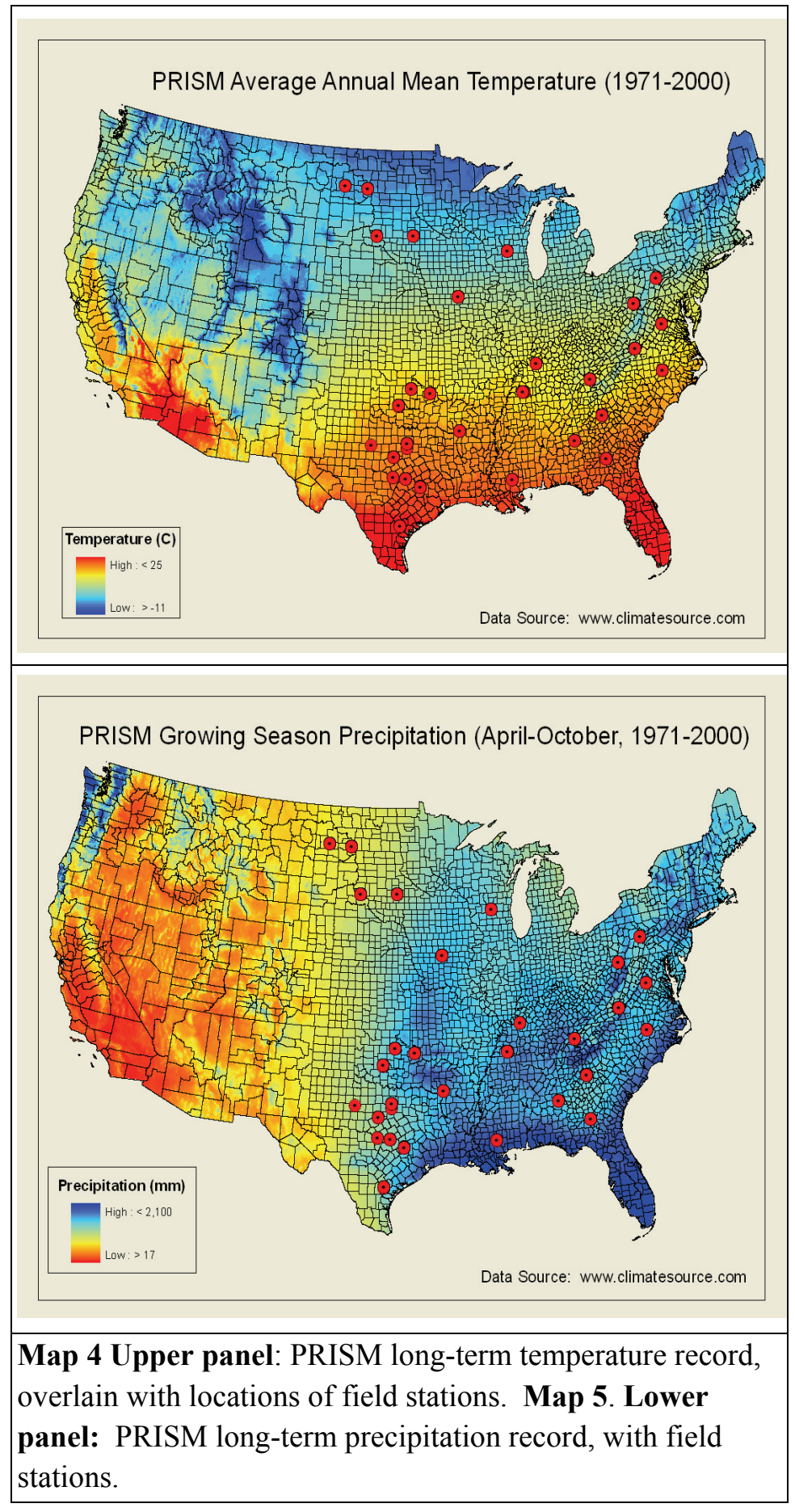
two North Dakota sites. The field sites also covered much of switchgrass' native distribution range (Map 1), and included three 
sites (in Texas, Oklahoma and North Dakota) that were west of the switchgrass range illustrated in Map 1.

Using the PRISM maps as input layers, ESRI ArcInfo 9.1 was then used to map potential switchgrass yields across the lower 48 states as a function of the long-term climate record, based on the multiplicative optimum model. The results were calculated and mapped separately for each ecotype (Maps 6 and 7). Even though the model was applied to all areas of the contiguous U.S, it is important to note that application of the model outside of its statistically validated boundaries (approximated by the red dots in Map 4) extrapolates beyond the theoretical limits of the model, and there could be region-specific differences that have not been identified. Nevertheless, the exercise does predict switchgrass yields across its native range, and suggests potential yields for switchgrass planted outside that native range.

Areas of Map 6 and 7 that project relatively high yields correlated reasonably well with the native range (Map 1). High yields for lowland varieties were predicted in parts of the southwest, and for both ecotypes in the Pacific Northwest, but did not extend beyond the Rocky Mountains and the deserts of the interior, where temperature and precipitation extremes appear to limit growth. Predictions in the Northwest region are not as statistically robust as those east of the Rockies, given the input data set, but are supported by USDA field trials from Washington State (Fransen et al. 2006) which, although not published in the primary literature, indicate that switchgrass can be established and grow in the Pacific Northwest region. Without a model responsive to climatic variables (e.g., the multiplicative optimum model, or M.O.M.), projections outside the previously known range would not be possible, thus the M.O.M. represents an advance over database projections with only historical foundations, such as ORECCL (MAP 7).

Results from this initial modeling effort suggest that lowland ecotypes would have a higher maximum yield than upland ecotypes, and that production would peak in the southeast, midAtlantic, and midwest states. Both conclusions are consistent with the literature (Sladden et al. 1991, McLaughlin and Kszos 2005, Casler et al. 2004, and Casler 2005). Based on field observations, however, upland varieties (planted and naturally occurring) predominate in more northerly latitudes and lowland in more southerly latitudes. This effect was not especially well represented in the model, where predicted lowland yields were indeed higher than upland yields in the south, but were similar to, or slightly higher than, upland yields in the northern U.S. as well. Maximum production was predicted in the same latitudinal range for both ecotypes, which is not inconsistent with existing data (Figures 5-7). Further north, the model predicted similar yields in both ecotypes, although there were no lowland ecotype yield data further north than Iowa to inform the model (Map 5, Figures 5 and 6). There are some indications that winter injury may limit survival of lowland ecotypes in the far north (Parrish and Fike 2005), and therefore, even though the model does not predict strong ecotypic differences at high latitudes, additional lowland (and upland) data are needed at high latitudes for an adequate evaluation. Another model validation is that the multiplicative optimum model did predict that switchgrass would grow if planted in the Pacific Northwest, as demonstrated by Fransen et al (2006), even though it was outside the native range of switchgrass. 

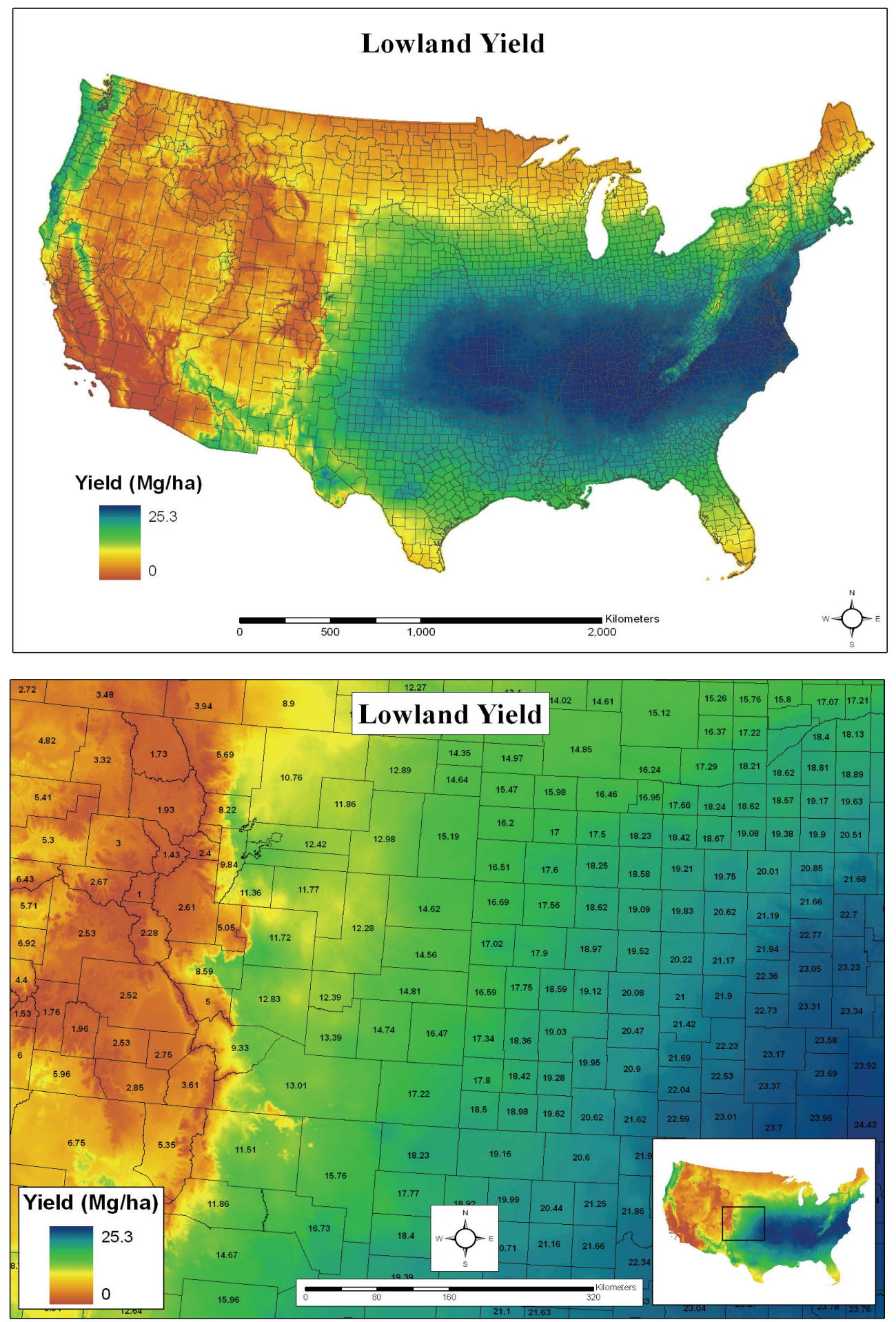

Map 6. Projections of optimal switchgrass yields for lowland cultivars using the multiplicative optimum model (M.O.M.) and climate output from PRISM.

Zoomed map (lower panel) shows mean yields at the county level. 

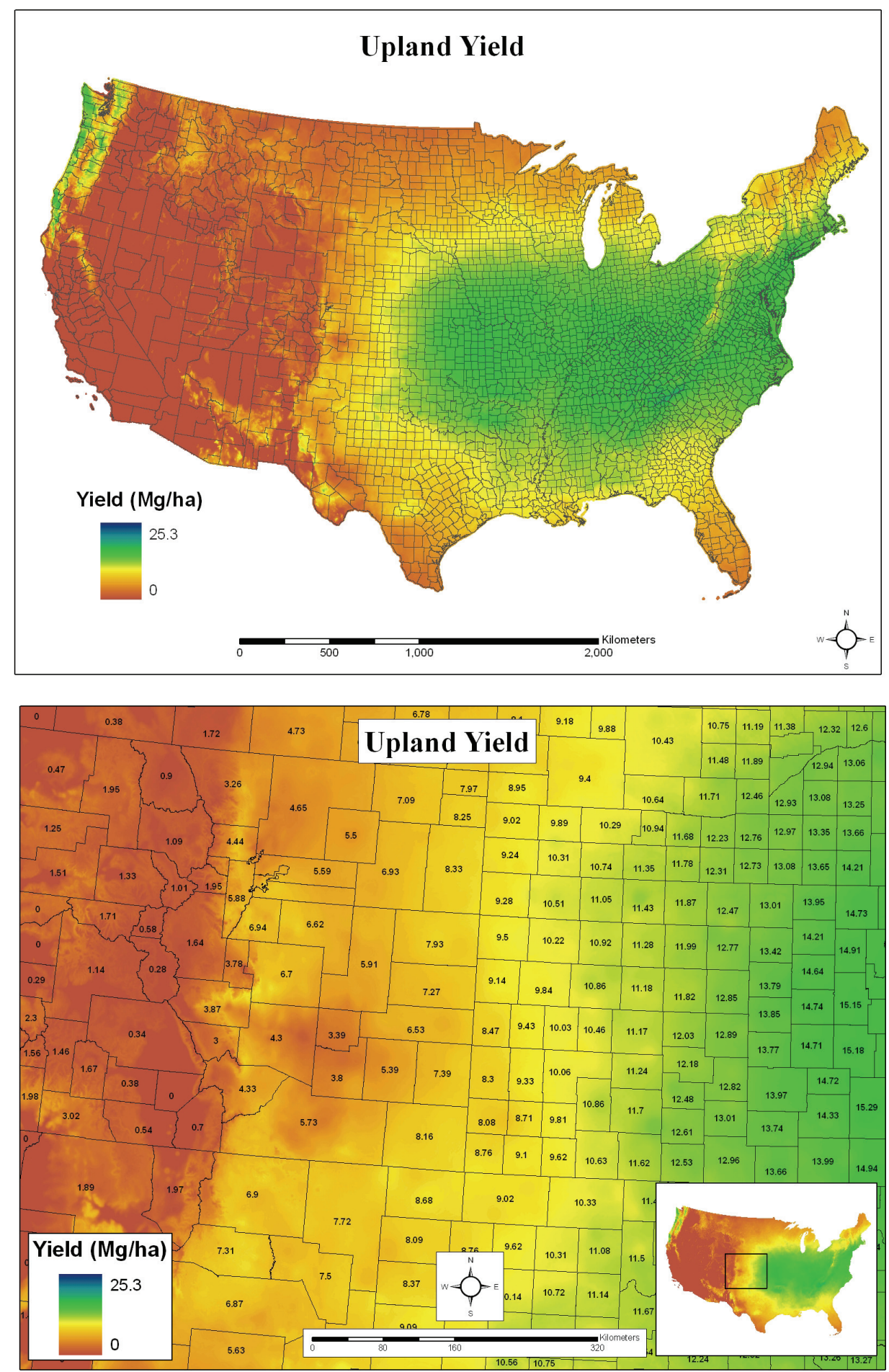

Map 7. Projections of optimal switchgrass yields for upland cultivars using the multiplicative optimum model (M.O.M.) and climate output from

PRISM. Zoomed map (lower panel) shows mean yields at the county level. 


\section{Comparison with ORECCL}

A county level database developed in 1996, ORECCL assigned each county within the U.S. a yield estimate (Graham et al. 1996, 1997). Outside the native range, or where agronomic experts had no observations or other indications that switchgrass cultivation was feasible, no estimates were made (Map 8, white areas). ORECCL did not distinguish between yields of upland and lowland ecotypes, but it did provide a high (optimistic), median, and low yield estimate for each county, based on expert opinion and the small amount of data available at the time. Yield estimates in ORECCL varied only from 7.8 (most pessimistic) to an optimistic range of 12.3 to $16.8 \mathrm{Mg} / \mathrm{ha}$, whereas the numerous field trials summarized here showed a range of yields from less than 2 to almost $40 \mathrm{Mg} / \mathrm{ha}$. Median predictions from ORECCL were generally similar to predictions of optimal yield in the upland ecotype the M.O.M., but the weather-based M.O.M. was able to accurately predict the lowest yields (below 5-6 Mg/ha), whereas ORECCL was not. Although many observed yields of lowland ecotype fields were within the ORECCL bounds of 7.8 to 16.8 , there was no relationship within that range between observed and predicted. That is to say that ORRECL estimates could not be used to distinguish yields within those boundaries, nor to extrapolate beyond them, whereas the M.O.M.'s $95^{\text {th }}$ percentile “optimistic" predictions were at least correlated with observed yields, such that the M.O.M. was better able to predict very high and very low yields, based on temperature and precipitation.

Some of the field trials in this data set were conducted in counties where ORECCL did not have a predicted yield. Three sites in Texas, Oklahoma and North Dakota were west of the potential switchgrass range suggested by ORECCL and illustrated in Map 8. Those sites produced yields from 2.2 to $8.0 \mathrm{Mg} / \mathrm{ha}$, admittedly at the very "pessimistic" end of the ORECCL spectrum, but more accurately predicted by the M.O.M. More interestingly, although not published in the primary literature, and not included in this analysis, USDA field trials in Washington State demonstrated that switchgrass can grow west of the native range for switchgrass (Fransen et al. 2006), an outcome envisioned by the M.O.M. (Maps 6 and 7), but not predictable using the ORECCL model approach of expert knowledge. 


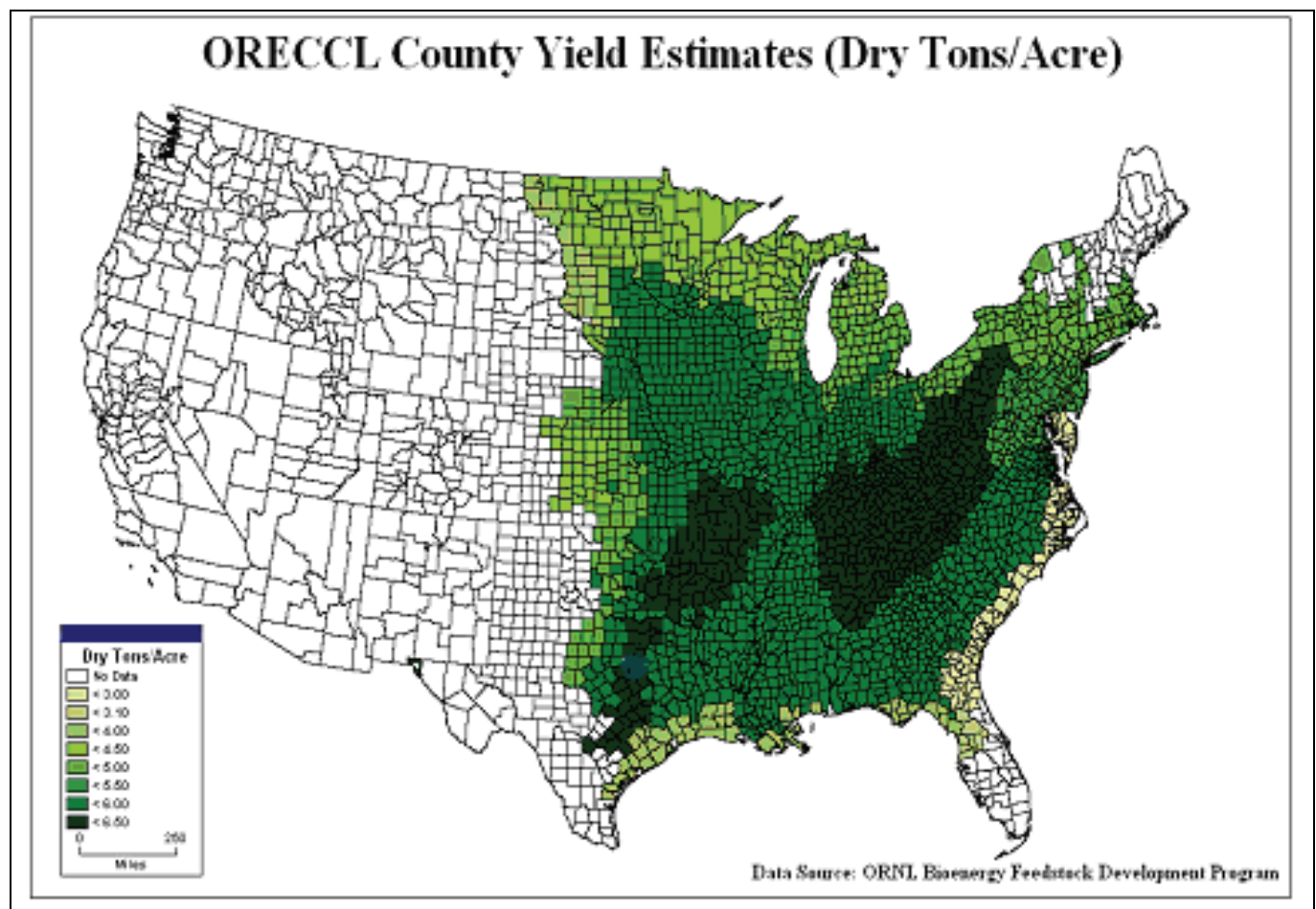

Map 8. ORECCL Estimates of Switchgrass Yield and Distribution, by county. 


\section{CONCLUSION}

This publication represents the first large compilation and analysis of switchgrass productivity data from sites across the U.S. Each observation has been identified by cultivar, ecotype, stand age, harvest system, $\mathrm{N}$ application rate, planting location, and year of harvest, adding data by communication with authors when needed. Additionally, national data bases were used to associate the observations with soil type and with temperature and precipitation records for the harvest year. Of the relationships established between yield and those variables, temperature and growing season precipitation were identified as the most predictive of yield. Regression-based modeling using the $95^{\text {th }}$ percentiles revealed patterns of resource limitation which could be used to predict the optimal yield associated with a given weather pattern. Although this multiplicative optimum approach over-predicted average yields, the relationships with temperature and precipitation were apparent in the upper bounds of the full data set, indicating only that there were additional factors contributing to yield reductions. As a result, the final map of potential yields across the U.S. is distinctly optimistic, assuming other factors are ideal. It serves as an indicator only of potential yields, and relative yields among locations, at least until the effects of other limiting factors can be quantified.

These analyses and projections may be best viewed as a first step towards more accurately predicting switchgrass yields. Although empirically based, the multiplicative optimum model showed promise as a means to associate potential yield with environmental parameters. Clearly there is significant room for improvement, and this will not be the final answer. That the initial M.O.M. model was not able to predict "typical" yields is not surprising, for several reasons. First, experimental data were unevenly distributed across the continuum of potential environments, with fairly large gaps limiting the ability to pinpoint response thresholds. Secondly, although the model relies on temperature and precipitation relationships, only 20 to $30 \%$ of the observed variation in yield was explained by those variables, with other variables reducing yields below the modeled optimum yields. This emphasizes the conclusion that other genetic and environmental factors and interactions play a significant role in determining switchgrass performance. These factors potentially include such variables as choice of cultivar, soil fertility (including elements other than nitrogen), soil $\mathrm{pH}$ and water-holding capacity, day length or temperature sum requirements, competition, herbivory, pests, disease, etc. It remains to be seen which of these variables would be most helpful in forecasting yield, keeping in mind that the relative impact of some of these factors may differ among cultivars. Finally, the published data were generated with different goals in mind, e.g., comparing cultivars, locations, crop management and agronomic practices, etc. Any relationships between yield and physical environment have thus been unavoidably confounded by inherent differences in productivity among cultivars, and by the variety of management regimes employed.

Future versions of the model might be improved using one or more of the following approaches:

1) Refining the predictive equations to more accurately predict response to temperature and precipitation, perhaps by choosing an alternate temperature parameter, or definition of growing season endpoints, or by changing bin sizes or percentile yield value used. 
2) Using minimum as well as maximum yields in relation to environmental resources to help control for unmeasured factors influencing yield (Lancaster and Belyea 2006).

3) Limiting the analysis to cultivars for which more than 10 or 20 observations are available, or eliminating cultivars that have repeatedly demonstrated poor performance, with the rationale that those varieties would eventually be abandoned in favor of higher-yielding cultivars.

4) Controlling statistically for the significant correlations among observations, i.e., the large, but variable number of observations that may be associated with a given site and year, resulting in an uneven distribution with respect to the independent climate variables.

5) Incorporating more management detail into yield predictions, e.g. adding stand age, number of harvests per year, or $\mathrm{N}$ application to the equations.

6) Adding other predictor variables such as growing degree days or accumulated solar radiation

It may also be decided that other modeling approaches (mechanistic or empirical) will be more useful for predicting yield than the model used here. The Miami model or the more statistically intensive quantile regression (through the full data set rather than through binned data) seem the most promising empirical models, yet they may also need to consider some of the factors suggested above.

In conclusion, the statistical model evaluated here shows promise for elucidating the cause and effect relationships relating variation in switchgrass yield to environmental variation, yet it needs to be improved, perhaps more carefully incorporating genetic differences or genetic $\mathrm{x}$ environmental interactions. Future analyses would do well to consider a range of statistical models, being aware of the trade-off between simplicity and accuracy, as well as considering the possibility of adapting a process-based yield model. Success with any of these techniques will improve our understanding of the limits of feedstock productivity, abundance, distribution, costs, and ability to supply a nascent cellulosic ethanol industry as an alternative to fossil fuel and gasoline-based transportation systems.

\section{REFERENCES}

Berdahl, J. D., A. B. Frank, J. M. Krupinsky, P. M. Carr, J. D. Hanson, and H.A. Johnson. 2005. Biomass yield, phenology and survival of diverse cultivars and experimental strains in western North Dakota. Agronomy Journal 97: 549-555.

Bouton, J.H. 2002. Bioenergy crop breeding and production research in the southeast. Final report for 1996 to 2001. ORNL/SUB-02-19XSV810C/01 Available on-line [http://www.osti.gov/bridge/]

Cade, B.S., Terrell, J.W., and R. L. Schroeder. 1999. Estimating effects of limiting factors with regression quantiles. Ecology 80: 311-323.

Casler, M.D. 2005. Ecotypic variation among switchgrass populations from the northern USA. Crop Science 45:388-398. 
Casler, M.D., and A.R. Boe. 2003. Cultivar x environment interactions in switchgrass. Crop Science 43: 2226-2233.

Casler, M.D., K.P. Vogel, C.M. Taliaferro and R.L Wynia. 2004. Latitudinal adaptation of switchgrass populations. Crop Science 44: 293-303.

Casler, M.D., K.P. Vogel, C.M. Taliaferro, N.J. Ehlke, J.D. Berdahl, E.C. Brummer, R.L. Kallenbach, C.P. West and R.B. Mitchell. 2007. Latitudinal and longitudinal adaptation of switchgrass populations. Crop Science. 47:2249-2260.

Cassida, K.A., T.L. Kirkpatrick, R.T. Robbins, J.P. Muir, B.C. Venuto and M.A. Hussey. 2005a. Plant-parasitic nematodes associated with switchgrass (Panicum virgatum L.) grown for biofuel in the south-central United States. Nematropica 35 (1): 1-10.

Cassida, K.A., J.P. Muir, M.A. Hussey, J.C. Read, B.C. Venuto, and W.R. Ocumpaugh. 2005b. Biomass yield and stand characteristics of switchgrass in south central U.S. environments. Crop Science 45: 673-681.

Di Virgilio, N., A. Monti and G. Venturi 2007. Spatial variability of switchgrass (Panicum virgatum L.) yield as related to soil parameters in a small field. Field Crops Research. 101:232239.

Energy Information Administration (EIA) 2006a. Assumptions to the Annual Energy Outlook, 2006. Report \#:DOE/EIA-0554

http://www.eia.doe.gov/oiaf/archive/aeo06/assumption/pdf/0554(2006).pdf

Energy Information Administration (EIA) 2006b. Energy Basics 101- U.S. Petroleum Consumption http://tonto.eia.doe.gov/dnav/pet/pet cons psup de nus mbblpd a.htm

Evers, E.W. and M.J. Parsons 2003. Soil type and moisture level influence on Alamo switchgrass emergence and seedling growth. Crop Science. 43:288-294.

Ferrell, J.E., Wright, L.L. and G.A. Tuskan 1995. Research to develop improved production methods for woody and herbaceous crops. In ISBN: CONF-9508104-1 pp. 197-206. URL: www.osti.gov/servlets/purl/102149-ZZrAk9/webviewable/

Fike, J.H., Parrish, D. J., Wolf, D.D., Balasko, J.A., Green Jr., J. T., Rasnake, M., and J.H. Reynolds. 2006a. Long-term yield potential of switchgrass-for-biofuel systems. Biomass \& Bioenergy 30: 198-206.

Fike, J.H., D. J. Parrish, D. D. Wolf, J.A. Balasko, J. T. Green Jr., M. Rasnake, and J.H. Reynolds. 2006b. Switchgrass production for the upper southeastern USA: Influence of cultivar and cutting frequency on biomass yields. Biomass and Bioenergy 30: 207-213. 
Fransen, S.C., H.P. Collins, and R.A. Boydston. 2006. Perennial warm-season grasses for biofuels. In Proceedings, 2006 Western Alfalfa and Forage Conference, December 11-13, 2006. Reno, Nevada.

Fuentes, R.C., and C.M. Taliaferro. 2002. Biomass yield stability of switchgrass cultivars. Trends in New Crops and New Uses. J. Janick and A. Whipkey (eds.). ASHS Press, Alexandria, VA. (pp. 276-282.)

Graham, R.L., L.J. Allison, and D.A. Becker. 1996. "ORRECL- Oak Ridge Energy Crop County Level Database". Pgs 522-529. In Proceedings of Bioenergy '96--The Seventh National Bioenergy Conference, Sept. 15-19, Nashville, Tennessee. Southeastern Regional Biomass Energy Program, Muscle Shoals, AL.

Graham, R.L., L.J. Allison and D.A. Becker 1997. "ORECCL - Oak Ridge Energy Crop County Level Database". Pgs 205-213. In Making a business from biomass in energy, environment, chemical, fibers and materials. Proceedings of the 3rd Biomass Conference of the Americas, August 24-28, Montreal, Quebec. R.P. Overend and E. Chornet (eds). Elsevier Science, Inc. New York, New York.

Gunter, L.E., G.A. Tuskan and S.D. Wullschleger 1996. Diversity among populations of switchgrass based on RAPD markers. Crop Science. 36: 1017-1022.

Hopkins, A.A., C.M. Taliaferro, C.D. Murphy and D. Christian 1996. Chromosome number and nuclear DNA content of several switchgrass populations. Crop Science. 36: 1192-1195.

Hultquist, S.J., K.P. Vogel, D.J. Lee, K. Arumuganathan and S. Kaeppler 1997. DNA content and chloroplast DNA polymorphisms among switchgrasses from remnant midwestern prairies. Crop Science. 37: 595-598.

Jager, H.I., Hargrove, W.W., Brandt, C.C., King, A.W., Olson, R.J., Scurlock, J.M.O., and K.A. Rose 2000. Constructive contrasts between modeled and measured climatic responses over a regional scale. Ecosystems 3: 396-411.

Jefferson, P.G., W.P. McCaughey, K. May, J. Woosaree and L. McFarlane 2004. Potential utilization of native prairie grasses from western Canada as ethanol feedstock. Canadian Journal of Plant Science. 84:1067-1075.

Kiniry, J.R., C.R. Tischler, and G.A. Van Esbroeck 1999. Radiation use efficiency and leaf $\mathrm{CO}_{2}$ exchange for diverse $\mathrm{C}_{4}$ grasses. Biomass and Bioenergy 17: 95-112.

Kiniry, J.R., K.A. Cassida, M.A. Hussey, J.P. Muir, W. R. Ocumpaugh, J.C. Read, R.L. Reed, M.A. Sanderson, B.C. Venuto, and J.R. Williams 2005. Switchgrass simulation by the ALMANAC model at diverse sites in the southern U.S. Biomass and Bioenergy 29: 419-425. 
Kiniry, J.R., M.A. Sanderson, J.R. Williams, C.R. Tischler, M.A. Hussey, W. R. Ocumpaugh, J.C. Read, G.Van Esbroeck, and R.L. Reed 1996. Simulating Alamo switchgrass with the ALMANAC model. Agronomy Journal 88: 602-606.

Lancaster, J. and L.R. Belyea 2006. Defining the limits to local density:alternative views of abundance-environment relationships. Freshwater Biology 51: 783-796.

Lee, D.K. and A. Boe 2005. Biomass production of switchgrass in central South Dakota. Crop Science 45:2583-2590.

Lemus, R., C.E. Brummer, K.J. Moore, N.E. Molstad, L.C. Burras, and M.F. Barker 2002. Biomass yield and quality of 20 switchgrass populations in southern Iowa, USA. Biomass and Bioenergy 23:433-442.

Lemus, R.W. 2004. Switchgrass as an energy crop: Fertilization, cultivar, and cutting management. Ph.D. Dissertation, Virginia Polytechnic Institute and State University http://scholar.lib.vt.edu/theses/available/etd-01292004115043/unrestricted/Roque Lemus Dissertation.pdf

Lieth, H. 1975. Modeling the primary productivity of the world. In: Lieth H, Whittaker RH, editors. Primary productivity of the biosphere. New York: Springer-Verlag

Madakadze, I.C., B.E. Coulman, P. Peterson, K.A. Stewart, R. Samson and D.L. Smith 1998a. Leaf area development, light interception, and yield among switchgrass populations in a shortseason area. Crop Science. 38:827-834.

Madakadze, I., B.E. Coulman, K. Stewart, P. Peterson, R. Samson and D.L. Smith 1998b. Phenology and tiller characteristics of big bluestem and switchgrass cultivars in a short growing season area. Agronomy Journal. 90: 489-495.

McLaughlin, S.B. and L.A. Kszos 2005. Development of switchgrass (Panicum virgatum) as a bioenergy feedstock in the United States. Biomass \& Bioenergy. 28: 515-535.

MODIS Satellite Data via USGS:

http://edcdaac.usgs.gov/modis/dataproducts.asp

Moreira, N. 2005. Growing expectations: new technology could turn fuel into a bumper crop. Science News. 168: 218-220.

Muir, J. P., M.A. Sanderson, W. R. Ocumpaugh, R.M. Jones, and R.L. Reed 2001. Biomass Production of 'Alamo' switchgrass in response to nitrogen, phosphorous, and row spacing. Agronomy Journal 93: 896-901. 
Parrish, D.J. and J.H. Fike 2005. The biology and agronomy of switchgrass for biofuels. Critical Reviews in Plant Sciences. 24: 423-459.

Parton, W.J. Scurlock, J.M.O., Ojima, D.S., Gilmanov, T.G., Scholes, R.J., Schimel. D.S., Kirchner, T., Menaut, J-C., Seastedt, T., Garcia, E., Kamnalrut, A., and J.I. Kinyamario 1993. Observations and modeling of biomass and soil organic matter dynamics for the grassland biome worldwide. Global Biogeochemical Cycles 7(4): 785-809.

Pastor, J. \& W.M. Post 1985. Development of a linked forest productivity-soil process model. ORNL/TM-9519, Oak Ridge National Laboratory, Oak Ridge, TN USA. http://www.esd.ornl.gov/ wmp/LINKAGES/doc/ornl-9519.pdf

Porter, C. L. 1966. An analysis of variation between upland and lowland switchgrass, Panicum virgatum L., in central Oklahoma. Ecology, 47: 980- 992.

Reynolds, J.H., C.L. Walker and M.J. Kirchner 2000. Nitrogen removal in switchgrass biomass under two harvest systems. Biomass \& Bioenergy. 19: 281-286.

Rubio, G., J. Zhu,, and J.P. Lynch 2003. A critical test of the two prevailing theories of plant response to nutrient availability. American Journal of Botany 90: 143-152.

Sanderson, M.A., Read, J.C., and R.L. Reed 1999a. Harvest management of switchgrass for biomass feedstock and forage production. Agronomy Journal 91: 5-10.

Sanderson, M.A., Reed, R.L., Ocumpaugh, W.R., Hussey, M.A., Van Esbroeck, G., Read, J.C., Tischler, C.R., and F.M. Hons 1999b. Switchgrass cultivars and germplasm for biomass feedstock production in Texas. Bioresource Technology 67: 209-219.

Sanderson, M.A., R.L. Reed, S.B. McLaughlin, S.D. Wullschleger, B.V. Conger, D.J. Parrish, D.D. Wolf, C. Taliaferro, A.A. Hopkins, W.R. Ocumpaugh, M.A. Hussey, J.C. Read and C.R. Tischler 1996. Switchgrass as a sustainable bioenergy crop. Bioresource Technology. 56: 83-93.

Sanderson, M.A., R.R. Schnabel, W.S. Curran, W.L. Stout, D. Genito, and B.F. Tracy 2004. Switchgrass and big bluestem hay, biomass, and seed yield response to fire and glyphosate treatment. Agronomy Journal 96: 1688-1692.

Sladden, S.E., Bransby, D.I., and G.E. Aiken 1991. Biomass yield, composition, and production costs for eight switchgrass varieties in Alabama. Biomass and Bioenergy. 1: 119-122.

Stubbendieck, J., S.L. Hatch and C.H. Butterfield 1992. North American Range Plants, $4^{\text {th }}$ ed. University of Nebraska Press, Lincoln, NE and London.

Thomason, W.E., Raun, W.R., Johnson, G.V., Taliaferro, C.M., Freeman, K.W., Wynn, K.J. and R.W. Mullen 2004 Switchgrass response to harvest frequency and time and rate of applied nitrogen. Journal of Plant Nutrition 27: 1199-1226. 
Turhollow, A.F. 1991. Screening herbaceous lignocellulosic energy crops in temperate regions of the United States. Bioresource Technology. 36:247-252.

U.S. Department of Energy (DOE) 2006. Breaking the biological barriers to cellulosic ethanol: A research roadmap resulting from the biomass to biofuels workshop. December 7-9, 2005.

Rockville, Maryland. Released June, 2006. DOE/SC-0095.

http://30x30workshop.biomass.govtools.us/default.aspx?menu=support

Vogel, K.P., A.A. Hopkins, K.J. Moore, K.D. Johnson and I.T. Carlson 2002. Winter survival in switchgrass populations bred for high IVDMD. Crop Science. 42:1857-1862.

Wright, L. 2007. Historical perspective on how and why switchgrass was selected as a "model" high-potential energy crop. ORNL/TM-2007/109. Available through http://www.osti.gov/bridge. 